NBER WORKING PAPER SERIES

\title{
LEARNING ABOUT ACADEMIC ABILITY AND THE COLLEGE DROP-OUT DECISION
}

\author{
Todd R. Stinebrickner \\ Ralph Stinebrickner \\ Working Paper 14810 \\ http://www.nber.org/papers/w14810
NATIONAL BUREAU OF ECONOMIC RESEARCH
1050 Massachusetts Avenue
Cambridge, MA 02138
March 2009

We appreciate comments from seminar participants at New York University, Rochester, Yale, Syracuse, Simon Fraser, NBER, The winter meetings of the Econometric Society, and The Analytical Labor Conference at the University of Chicago. We are grateful for support from The Mellon Foundation, The Spencer Foundation, The National Science Foundation, SSHRC, and Berea College. This work would not have been possible without the extraordinary work of Lori Scafidi and the assistance of Diana Stinebrickner, Pam Thomas, and Albert Conley. The views expressed herein are those of the author(s) and do not necessarily reflect the views of the National Bureau of Economic Research.

NBER working papers are circulated for discussion and comment purposes. They have not been peerreviewed or been subject to the review by the NBER Board of Directors that accompanies official NBER publications.

(C) 2009 by Todd R. Stinebrickner and Ralph Stinebrickner. All rights reserved. Short sections of text, not to exceed two paragraphs, may be quoted without explicit permission provided that full credit, including $\odot$ notice, is given to the source. 
Learning about academic ability and the college drop-out decision

Todd R. Stinebrickner and Ralph Stinebrickner

NBER Working Paper No. 14810

March 2009

JEL No. I2,I21,I23,I3,J24

\begin{abstract}
$\underline{\text { ABSTRACT }}$
We use unique data to examine how college students from low income families form expectations about academic ability and to examine the role that learning about ability and a variety of other factors play in the college drop-out decision. From the standpoint of satisfying a central implication from the theory of drop-out, we find that self-reported expectations data perform well relative to standard assumptions employed in empirical work when it is necessary to explicitly characterize beliefs. At the time of entrance, students tend to substantially discount the possibility of bad grade performance, with this finding having implications for understanding the importance of the option value of schooling. After entrance, students update their beliefs in a manner which takes into account both initial beliefs and new information, with heterogeneity in weighting being broadly consistent with the spirit of Bayesian updating. Learning about ability plays a very prominent role in the drop-out decision. Among other possible factors of importance, while students who find school to be unenjoyable are unconditionally much more likely to leave school, this effect arises to a large extent because these students also tend to receive poor grades. We end by examining whether students whose grades are lower than expected understand the underlying reasons for their poor grade performance.
\end{abstract}

Todd R. Stinebrickner

Department of Economics

University of Western Ontario

London, Ontario, N6A 5C2

CANADA

and NBER

trstineb@uwo.ca

Ralph Stinebrickner

Dept. of Mathematics

Berea College

Berea, KY 40404

ralph_stinebrickner@berea.edu 


\section{Introduction}

While it is well recognized that students from low income families have much higher college drop-out rates than other students, little is know about the relative importance of various possible explanations for the educational outcomes of this group. ${ }^{1}$ In this paper we provide direct, new evidence about this issue by taking advantage of a unique longitudinal survey that provides information about a comprehensive set of factors that theory suggests might influence the drop-out decision. The project, The Berea Panel Study, takes place at a school, Berea College, that is valuable for an in-depth case study of this sort because it operates under a mission of providing educational opportunities to students from low income families.

Much previous research on educational attainment of low income students has focused on the role of credit constraints. Berea College offers a full tuition (and a large room and board) subsidy to all entering students. Stinebrickner and Stinebrickner (2003) (hereafter referred to as S\&S) found that, despite the fact that the direct costs of students at Berea are approximately zero (and perhaps negative), fifty percent of students do not graduate. ${ }^{2}$ S\&S (2008a) found that, in the aggregate, difficulties borrowing money to pay for consumption during school also do not play a particularly important role at Berea. Thus, it seems reasonable to believe that explanations unrelated to short-term credit constraints play an important role in determining drop-out. The goal of this work is to provide some of the first direct evidence about the relative importance of the most prominent alternative explanations.

We pay particular attention to perhaps the most prominent alternative explanation - that college drop-out arises as students learn about their academic ability after matriculation (Manski, 1989, Altonji, 1993, Carneiro et al., 2005, Cunha et al., 2005). The reality that little direct empirical evidence exists about the importance

\footnotetext{
${ }^{1}$ Bowen and Bok (1998) write "One large question is the extent to which low national graduation rates are due to the inability of students and their families to meet college costs, rather than to academic difficulties or other factors." Outside of economics, the most referenced work, Tinto (1975), suggests that whether a students drops out is strongly related to the student's degree of academic and social integration. However, while this theory has received much attention, Draper (2005) writes "It is less clear whether there is much direct empirical support for it, and certainly it is hard to find direct empirical tests of and challenges of it." The problem is primarily related to data limitations; it is often hard to even tell exactly what information is being used to proxy for social and academic integration (Draper, 2005; Beekhoven, 2002).

${ }^{2} \mathrm{~S} \& S(2003)$ find that these drop-out rates are generally similar to those of low income students elsewhere.
} 
of this explanation stems from the difficulty in characterizing what a person has learned about his academic ability during school. The fundamental problem is that identifying beliefs (expectations) about a factor such as ability at any particular point in time is difficult using standard choice data because a particular behavior may be consistent with multiple characterizations of preferences and expectations (Manski, 2002, 2004). In response to this fundamental identification issue, researchers in economics have recently paid much closer attention to the virtues of eliciting self-reports of subjective probabilities using carefully worded survey questions (Dominitz, 1998; Dominitz and Manski, 1996, 1997). ${ }^{3}$ However, even with this development in survey methodology, there are practical difficulties related to the timing of surveys that are often encountered if one wishes to characterize learning. In the drop-out context, providing relevant evidence about how beliefs change requires the elicitation of beliefs both at the time of entrance and at a time close to when the decision of whether to remain in school is made, with this task being difficult in standard longitudinal survey designs which typically contact students at most once a year.

We are able to overcome the standard difficulty in characterizing what a person has learned about his academic ability during school because our initiation of the BPS gave us the flexibility to elicit self-reported beliefs at multiple times each year, starting at the time of college entrance. As such, in the process of providing a new understanding of the drop-out decision, this work is able to make a second contribution - providing some of the first evidence about how agents update subjective beliefs in response to the arrival of new information. Manski (2004) writes that there exists a "critical need for basic research on expectations formation."4

After describing the Berea Panel Study in Section II, we next take a detailed look at beliefs. Section III examines beliefs at the time of entrance. We find that students are, on average, considerably too optimistic about their grade performance at entrance. This result is inconsistent with the standard assumption employed in empirical work when it is necessary to explicitly characterize beliefs. Given this inconsistency, we discuss the

\footnotetext{
${ }^{3}$ For early work in economics see Juster (1966).

${ }^{4}$ For work that has measured revisions to expectations, see , for example, Dominitz, 1998; Dominitz and Manski, 2003; Dominitz and Hung, 2003; Delevande, 2006; Lochner, 2007; Madeira, 2007; Zafar, 2008.
} 
implications of our finding that students are overly optimistic for understanding the role that the option value of schooling plays in the college entrance decision and college drop-out decision (Manski, 1989; Altonji, 1993; Cunha et al. 2005; Stange, 2007). Section IV examines expectations formation. We find that individuals update their beliefs at the end of a semester in a reasonable manner which, for example, takes into account both their beliefs at the beginning of the semester (prior beliefs) and the information (noisy signal) that they receive during the semester in the form of semester grades. Further, while the goal of this work is not to test any particular model of learning, we find that heterogeneity in updating conditional on a person's prior beliefs and noisy signal can be predicted by individual-specific perceptions that a Bayesian learning model suggests would be of importance.

We then turn to understanding the importance of various explanations for drop-out. Perhaps the most important potential use of self-reported expectations data is to reduce the reliance of arbitrary assumptions in the estimation of behavioral models. ${ }^{5}$ However, because the estimation of a full learning model of the drop-out decision is beyond the scope of this paper, in Section V we estimate simple models of drop-out. We estimate both models in which independent variables are derived from a student's stock of information at the time of the drop-out decision and models in which independent variables are derived from the amount that the student has learned by the time of the drop-out decision. Our results indicate that learning about ability plays a particularly important role in the drop-out decision, and we discuss the importance of this finding for thinking about the option value of schooling. Among other possible factors of importance, our results show that, while students who find school to be unenjoyable are unconditionally much more likely to leave school, this effect arises to a large extent because these students also tend to receive poor grades. In Section VI we pay careful attention to students at the bottom of the grade distribution with a focus on examining whether these students understand the reasons for their worse than expected grade performance. We conclude in Section VII.

\footnotetext{
${ }^{5}$ The use of expectations data in the estimation of behavioral models is quite limited. Wolpin (1999), van der Klaauw (2000), and van der Klaauw and Wolpin (forthcoming) take advantage of expectations data in a different manner than what would be suggested by the data collected here - they show that self-reported expectations about future outcomes of interest can be used to increase the precision of estimators in models that make standard assumptions about beliefs.
} 
While interactions with respondents make us confident that students were comfortable with the survey questions we used to elicit expectations, it is worth noting that it will never be possible to directly examine how accurately self-reported expectations data represent a person's true beliefs. Instead, confidence in the usefulness of this sort of data is best accumulated by examining, as in Manski (2004), its performance across a variety of substantive contexts. As such, by and large, we take as our starting point that useful information about subjective beliefs can be elicited from carefully worded survey questions. Nonetheless, our findings provide perhaps the strongest evidence to-date for this starting point. Simple theory related to the drop-out decision suggests that both a person's actual grade point average in the first year and the person's beliefs about future grade performance at the end of the first year should be important predictors of whether a person returns to college after the first year. In Section $\mathrm{V}$ we find that this theoretical implication is satisfied when we measure beliefs about future grade performance directly using self-reported expectations data. However, this theoretical implication is not satisfied when we construct beliefs about future grade performance using standard assumptions employed in empirical work when it is necessary to explicitly characterize beliefs.

\section{The Berea Panel Study}

Berea College is located in central Kentucky and operates under a mission of providing an education to students from low income families. The BPS baseline surveys were administered to students in the first BPS cohort (the 2000 cohort) immediately before they began their freshman year classes in the fall of 2000 and were administered to students in the second BPS cohort (the 2001 cohort) immediately before they began their freshman year classes in the fall of 2001. The baseline surveys took advantage of recent advances in survey methodology (see e.g., Barsky et al., 1997, Dominitz, 1998, and Dominitz and Manski, 1996 and 1997) to collect information about students' expectations towards uncertain future events and outcomes, including academic performance, that could influence the drop-out decision. Substantial follow-up surveys were administered at the beginning and end of each subsequent semester to provide information about how expectations change over time, and time-use information was collected four times each semester using the 24hour time-diaries shown in the Appendix A (Stinebrickner and Stinebrickner, 2004; Stinebrickner and 
Stinebrickner, forthcoming A).

We examine learning during the first year of college, the period when the majority of attrition occurs. We focus on the 2001 BPS cohort because certain questions of interest for this paper were added after the 2000 cohort completed its first year at Berea. Because our interest in learning requires that we observe expectations about grade performance at two different points in time, we focus on students in the 2001 cohort who answered both our baseline survey and the survey that took place immediately before the beginning of the second semester. Three hundred seventy-five of $420(89 \%)$ matriculating students in this cohort completed our baseline survey. Three hundred twenty-five of these students were still in school at the beginning of the second semester and answered the survey which took place at that time. ${ }^{6}$

\section{Beliefs at the time of entrance}

We observe each student's first semester grade point average measured on a four point scale, $G P A_{l i}$, directly from administrative data. We elicit each student's subjective beliefs about the distribution of $G P A_{1 i}$ using survey Question A.2 (Appendix A) which was administered immediately before the start of classes in the first semester. Paying close attention to methodological suggestions in Dominitz (1998) and Dominitz and Manski $(1996,1997)$, the question asks each student to report the "percent chance" that his $G P A_{1 i}$ will fall in each of a set of mutually exclusive and collectively exhaustive categories, conditional on an expected level of study effort for the first semester, Expected_STUDY ${ }_{l i}$, that is elicited in Question A.1 (Appendix A).

Column 1 of Table 1A shows the subjective probabilities of first semester grade point average, $G P A_{l i}$, from Question A.2 averaged over the 325 students in our sample. Column 2 of Table 1A shows the proportion of students in the sample whose actual $G P A_{1 i}$ falls in each category. Comparing Column 1 and Column 2 of Table 1A reveals that, on average, individuals are too optimistic about their grade performance. For example, on average, individuals believe that the probability of obtaining a $G P A_{1 i}$ between 3.5 and 4.0 is .401 while, in

\footnotetext{
${ }^{6}$ The response rate on the survey at the beginning of the second semester was approximately $94 \%$. This implies that approximately half of the 50 students who answered the baseline survey but did not answer the survey at the beginning of the second semester had left school by the beginning of the second semester. While it would also be of interest to know how the beliefs about academic ability changed for these students (who are not in the sample used in this paper) between the time of entrance and the time of departure, the period between the beginning of the second semester and the beginning of the second year is the period with the highest amount of attrition.
} 
reality, only .234 of students actually receive a $G P A_{1 i}$ in this range. Similarly, on average, individuals believe that the probability of obtaining a $G P A_{l i}$ of less than 2.0 is .037 while, in reality, .141 of students actually receive a $G P A_{1 i}$ in this range. A chi square goodness-of-fit test rejects the null hypothesis that the distribution in Column 2 is obtained by sampling from the distribution in Column 1at all traditional levels of significance $(\text { chi square statistic }=139.8 \text { with } 5 \text { d.f. })^{7}$.

In empirical work, including structural estimation, in which it is necessary to characterize a person's beliefs about an uncertain outcome, the standard approach is to assume that the distribution describing the person's beliefs corresponds to the distribution of actual outcomes for people deemed by the econometrician to be "like" the person (typically) in observable ways. For example, this assumption in this context would imply that: 1) a student believes that, on average, his grades will be equal to the average grades of people deemed to be like him and 2) the student's uncertainty about his grade performance corresponds to the amount of variation in the actual grade outcomes of people deemed to be like him. Thus, the evidence from Table 1A does not support this standard assumption. In the remainder of this paper, we follow the convention in this empirical literature by referring to this assumption as Rational Expectations (RE).

The result that students assign too little probability to the poor academic outcomes arises as a combination of the fact that the mean of a student's subjective $G P A_{l i}$ distribution is, on average, biased upwards and the fact that, on average, students are more certain about their first semester grade point average than would be suggested by a Rational Expectations assumption. With respect to the former, we compute an approximate value of $\mathrm{E}\left(G P A_{l i}\right)$ for each person i from survey Question A.2 by assuming that the grade density is uniform within each of the mutually exclusive and collectively exhaustive grade categories. ${ }^{8}$ Referring to

\footnotetext{
${ }^{7}$ It may be desirable to combine the intervals $[1.0,2.0)$ and $[0.0,1.0)$ before performing the Chi square test but this has no effect on the conclusions from the test.

${ }^{8}$ The need to approximate is a disadvantage of using our information about the entire grade distribution to compute the expected value. Nonetheless, because we are confident that students are comfortable answering our Question A.2 about the entire grade distribution and because we find it appealing to compute expected values ourselves (rather than relying on students to use an appropriate definition of "expected" grade performance), we believe that, on net, the use of this question is desirable for our purposes. Hereafter, we largely ignore the presence of approximation error in the construction of this variable.
} 
this approximate mean as prior_mean ${ }_{i}$, the second to last entry in Column 1 of Table 1A shows that the average prior_mean ${ }_{i}$ for the 325 students in our sample is 3.22 while the last entry of Column 2 shows that the average $G P A_{1 i}$ is $2.88 .{ }^{9}$ With respect to the latter, the last entry in Column 1 of Table $1 \mathrm{~A}$ shows that, on average, the standard deviation of a student's subjective $G P A_{l i}$ distribution is .532 while the last entry of Column 2 shows that the standard deviation of actual $G P A_{1 i}$ is $.784 .{ }^{10}{ }^{11}$

Tables $1 \mathrm{~B}$ and $1 \mathrm{C}$, which show the results in Table 1A separately by whether a student's high school grade point average, $H S G P A_{i}$, is above or below the median in our sample, show that the RE assumption may be particularly problematic for some subgroups. The last rows of Table 1B show that the difference between the average prior_mean ${ }_{i}$ in the sample and the average $G P A_{l i}$ in the sample is .11 for students whose high school grade point average is above the median (3.275 vs. 3.164). However, the last rows of Table $1 \mathrm{C}$ show that this difference is .58 for students whose high school grade point average is below the median(3.161 vs. $2.579) .^{12}$

The option value of schooling arises because, when uncertainty exists about ability at the time of entrance, students benefit from a system in which they decide sequentially whether or not to stay in college as uncertainty is resolved. One possible definition of the option value of college attendance is the difference between the discounted expected utility of entering college under the current system in which a student decides

\footnotetext{
${ }^{9} \mathrm{~A}$ standard normal test rejects the null that the average prior_mean $n_{i}$ is the same as the average actual $G P A_{l i}$ at all traditional significant levels (test statistic $=8.05$ ).

${ }^{10}$ As above, we compute this latter number by assuming that the grade density is uniform within each of the mutually exclusive and collectively exhaustive grade categories in Question A.2.

${ }^{11}$ While the evidence in the previous paragraph suggests that prior_mean is far from a perfect predictor of first semester grade point average, we do find that prior_mean contains information about actual grade performance. In particular, in results not shown, regressing GPA $A_{1 i}$ on prior_mean $n_{i}$ yields an estimated coefficient (standard error) of .394 (.147) for prior_mean ${ }_{i}$. As can be seen in Table 2, the correlation between $G P A_{1 i}$ and prior_mean ${ }_{i}$ is .147.

${ }^{12}$ For students above the median, a standard normal test rejects the null hypothesis that the average prior_mean is the same as the average actual $G P A_{l i}$ at only significant levels greater than $.134(\mathrm{t}$-statistic $=1.50)$ while, for students below the median, this null hypothesis is rejected at all traditional significance levels $(\mathrm{t}$-statistic $=8.00)$. For students above the median, a chi square test easily rejects the null hypothesis that the distribution in Column 2 is obtained by sampling from the distribution in Column 1 at all traditional significance levels (chi square statistic $=$ 83.5 with 5 d.f.). A chi square test rejects the same null hypothesis for students whose high school grade point average is above the median at a significance level of .10 but not at .05 . (Chi square statistic=10.0 with 5 d.f.).
} 
sequentially (e.g., on a semester-by-semester basis) whether or not to remain in college and the discounted expected utility of entering college under the counterfactual in which a student who enters college must precommit to remaining in school until graduation. ${ }^{13}$ Thus, the option value will be lower if the student is more certain at the time of college entrance that he will graduate from college. The strong relationship consistently found in previous literature (and in Section $\mathrm{V}$ of this paper) between academic performance and college drop-out suggests that students who obtain high grades are typically well above the margin of indifference between being in and out of college. Then, our finding that even students who have relatively high actual probabilities of performing poorly believe that bad grade outcomes are very unlikely suggests that students may be substantially more certain than they should be that they will graduate from college. This suggests that students may perceive the option value to be substantially lower than what would be suggested by a Rational Expectations assumption.

From an additional survey question on the baseline BPS survey, we find additional, direct evidence that students are likely to perceive the option value to be substantially lower than what would be suggested by a Rational expectations assumption:

Question B What is the percent chance that you will eventually graduate from Berea College?

While approximately $60 \%$ of entering students in this cohort eventually graduate from Berea, on average, students believe that there is an $86 \%$ chance that they will graduate from Berea. ${ }^{14}$ In Section V we discuss what simple theory implies about the usefulness of this question in empirical models that examine the effect of learning on college drop-out. We find empirical evidence that the answers to this question contain valuable information.

Recent evidence that families of potential college students tend to substantially overestimate the direct

\footnotetext{
${ }^{13}$ This definition of the option value focuses on uncertainty about ability (Stange, 2007). One could also include in this definition the continuation value of starting school which is present even if no uncertainty exists about ability (Heckman, Lochner, and Todd, 2006; Heckman and Navarro, 2007).

${ }^{14}$ The graduation rates at Berea increased slightly from the earlier periods studied in S\&S (2003).
} 
costs of college has led to a concern that inaccurate information may lead to a situation where too few students choose to enter college (NCES, 2003). The evidence here raises the very real possibility that more accurate information about academic performance in college could lead to a situation where some students who are currently entering might decide not to enter. ${ }^{15}$

\section{Expectations formation: Changes in beliefs between time of entrance and second semester}

To study expectations formation in this section, we first measure revisions to expectations by comparing beliefs at the time of entrance to beliefs at the beginning of the second semester (Section IV.A). We then examine how students arrive at their new beliefs (Section IV.B).

\section{IV.A. Measuring revisions to expectations: Comparing beliefs at beginning of the $1^{\text {st }}$ and $2^{\text {nd }}$ semesters}

We examine revisions to expectations by comparing a student's subjective beliefs about $G P A_{l i}$ from Section III to the student's subjective beliefs about second semester grade point average, $G P A_{2 i}$. The latter beliefs were elicited using Question A.4 (Appendix A) which was administered immediately before the start of classes in the second semester. The question asks each student to report the "percent chance" that his $G P A_{2 i}$ will fall in each of a set of mutually exclusive and collectively exhaustive categories, conditional on an expected level of study effort in the second semester, Expected_STUDY $Y_{2 i}$, that is elicited in Question A.3 (Appendix A). ${ }^{16}$

Table 3 shows the subjective probabilities of $G P A_{2 i}$ from Question A.4 averaged over the 325 students in our sample. In much of the remainder of this paper we focus our attention by examining revisions to mean expectations. We compute an approximate value of $\mathrm{E}\left(G P A_{2 i}\right)$ for person i from survey Question A.4 in the same way as described in Section III. Referring to this approximate mean as posterior_mean ${ }_{i}$, the second-tolast entry of Table 3 shows that posterior_mean ${ }_{i}$ has an average value in our sample of 3.14. Comparing, in

\footnotetext{
${ }^{15}$ It is impossible to know from our data what effect accurate information would have on people who have chosen not to enter college. It is very possible that some of these people are incorrectly pessimistic about their college academic performance.

${ }^{16}$ Due in large part to a substantial number of required courses in the liberal arts curriculum, it is probably not unreasonable to believe that overall course difficulty tends to be generally similar between the 1 st and $2 \mathrm{nd}$ semesters.
} 
the first Column of Table 4, this value to the average prior_mean ${ }_{i}$ of 3.22 from Section III reveals that, on average, individuals are significantly revising their beliefs about grade performance between the start of the first semester and the start of the second semester. ${ }^{17}$ Further, this comparison tends to mask the full degree of updating that is taking place at the individual level since some individuals revise their beliefs upwards while others revise their beliefs downwards; on average, the absolute value of the difference between prior_mean ${ }_{i}$ and posterior_mean is $_{i} .289$.

\section{IV.B. How do students arrive at their new beliefs?}

\section{IV.B.1. Do new beliefs respond to new information?}

Central to theories of learning is the notion that individuals respond to new information. The new information that we consider is a person's first semester grade point average, $G P A_{1 i}$. Stratifying the sample by $G P A_{l i}$ we find sensible patterns of updating by $G P A_{1 i}$ group. For example, in the second column of Table 4 we show the average prior_mean ${ }_{i}$ and the average posterior_mean ${ }_{i}$ for students in the top-third of the actual $G P A_{1 i}$ distribution. In the third column of Table 4 we show the average prior $_{\text {mean }}$ and the average posterior_mean ${ }_{i}$ for students in the bottom third of the actual GPA $A_{1 i}$ distribution. While the difference in the average prior_mean ${ }_{i}$ between the groups is relatively small, .08 , the difference in the average posterior_mean ${ }_{i}$ between the groups becomes substantial, .50, after the groups observe large differences in first semester grade performance. $^{18}$

\section{IV.B.2. Do new beliefs depend on previous beliefs?}

It is natural to believe that new beliefs may depend on previous beliefs, even after taking into account the new information that is observed. We find strong evidence of this; prior_mean ${ }_{i}$ and $G P A_{1 i}$ are both important predictors of posterior_mean ${ }_{i}$ when we use our entire sample to estimate a regression of the form

(1) posterior_mean ${ }_{i}=\beta_{0}+\beta_{1}$ prior_mean ${ }_{i}+\beta_{2} G P A_{1 i}+\mathrm{u}_{\mathrm{i}}$

\footnotetext{
${ }^{17}$ The null hypothesis that the average mean in the population is the same between the two semesters is rejected at traditional significance levels (p-value .0017).

${ }^{18}$ The null hypothesis that the difference in the average posterior means between the groups is the same as the difference in the average prior means between the groups is easily rejected at all traditional significance levels.
} 
by Ordinary Least Squares (OLS). Specifically, Column 1 of Table 5 shows that the point estimates (standard errors) for $\beta_{1}$ and $\beta_{2}$ are $.396(.051)$ and $.245(.019)$, respectively. The null hypothesis that $\beta_{1}=0$ and the null hypothesis that $\beta_{2}=0$ are each rejected with the tests having t-statistics of 7.76 and 12.89 , respectively.

\section{IV.B.3 Can we understand heterogeneity in updating conditional on prior_mean ${ }_{\mathrm{i}}$ and $\mathrm{GPA}_{1 \mathrm{i}}$ ?}

In this section we examine whether we can provide any evidence about why substantial heterogeneity exists in posterior_mean ${ }_{i}$ for students who have the same prior_mean ${ }_{i}$ and $G P A_{1 i}$. We stress that it is not our objective to provide a formal test of any specific model of learning. Indeed, as will be discussed in detail later, doing so will always be extremely difficult using real-world data. ${ }^{19}$ Nonetheless, given that little is understood about the process governing expectations formation in the real world, we turn to a particularly prominent model of learning - the Bayesian model - to obtain some theoretical implications describing why heterogeneity may exist in updating. Whether, in practice, these implications are useful for predicting heterogeneity is examined by taking advantage of survey questions that were motivated by the theory.

Suppose that student i's grade point average on a 4.0 scale in a particular semester $\mathrm{t}$ is determined by the sum of a constant $\theta_{\mathrm{i}}$ that represents his person-specific, permanent academic ability (or academic preparation that is essentially permanent in nature at time of college entrance) and a random variable $\varepsilon_{\mathrm{ti}}{ }^{20}$; (2) $G P A_{t i}=\theta_{i}+\varepsilon_{t i}$.

We begin by describing the model under assumptions about $\varepsilon_{\mathrm{ti}}$ that would be standard in a textbook version -

\footnotetext{
${ }^{19}$ Moreover, doing so runs somewhat counter to perhaps the strongest rationale for collecting survey data on expectations - that it allows researchers estimating behavioral models to move away from somewhat arbitrary, untestable assumptions about the learning process in favor of relatively flexible specifications for the learning process. Providing evidence about whether agents update in, for example, a Bayesian manner has been the focus of experimental work.

${ }^{20}$ Although we tend to refer to $\theta_{i}$ as ability, we note that it is not necessarily literally true that changes in beliefs about $\theta_{i}$ entirely represent changes in beliefs about ability. For example, a person who enters school with a belief that the mean of the school's grade distribution is higher than it actually is may reduce his beliefs about his own mean GPA after the time of entrance even if he has not learned anything about his ability relative to other students at the school. However, what seems important is that, if misperceptions about average grades at the school exist at the time of entrance, they are not likely to be overly large. Thus, students of perhaps the most policy interest - those who perform very poorly - are almost certainly learning primarily about something other than their relative position in the grade distribution when they see grades that are much lower than expected. Regardless, if one wanted to be technically correct, $\theta_{i}$ would be referred to as mean GPA for person i, and for much of this paper the distinction is not of particular importance.
} 
that $\varepsilon_{\mathrm{ti}}$ represents semester randomness in grades that is purely idiosyncratic in nature, that $\varepsilon_{\mathrm{ti}}$ is not observed directly by students, and that beliefs about $\varepsilon_{\mathrm{ti}}$ are fixed for all $\mathrm{t}^{21}$

Learning takes place about $\theta_{\mathrm{i}}$. Beliefs about $\theta_{\mathrm{i}}$ at the beginning of the first semester $(\mathrm{t}=1)$ are characterized by a distribution that we refer to as the "prior" distribution. We refer to the mean and variance of this prior distribution of ability for person i as the prior mean and prior variance. After the first semester, the student observes his first semester grade point average $G P A_{l i}=\theta_{\mathrm{i}}+\varepsilon_{1 \mathrm{i}}$ which represents a noisy signal of academic ability. This noisy signal (hereafter often referred to simply as the "signal") is used in conjunction with the prior distribution of $\theta_{\mathrm{i}}$ and the belief about the distribution of $\varepsilon_{\mathrm{ti}}$ to generate the distribution that characterizes the person's beliefs about $\theta_{\mathrm{i}}$ at the beginning of the second semester $(\mathrm{t}=2)$. Hereafter, we refer to this $\mathrm{t}=2$ distribution as the "posterior" distribution. We refer to the mean and variance of this distribution of ability for person $\mathrm{i}$ as the posterior mean and posterior variance.

From our survey questions it is not possible to identify the entire prior distribution or the entire posterior distribution of $\theta_{i}$. For example, because survey question A.2 (Appendix A) elicits information about $G P A_{1 i}=\theta_{\mathrm{i}}+\varepsilon_{1 \mathrm{i}}$, an attempt to identify the prior distribution of $\theta_{\mathrm{i}}$ from this question is confounded by the presence of $\varepsilon_{1 \mathrm{i}}$ - with the problem being that a student's beliefs about $\varepsilon_{1 \mathrm{i}}$ are not observed. ${ }^{22}$ Similarly, because survey question A.4 (Appendix A) elicits information about $G P A_{2 i}=\theta_{\mathrm{i}}+\varepsilon_{2 \mathrm{i}}$, an attempt to identify the posterior distribution of $\theta_{\mathrm{i}}$ from this question is confounded by the presence of $\varepsilon_{2 \mathrm{i}}$. However, under the assumption that students believe that $\mathrm{E}\left(\varepsilon_{\mathrm{ti}}\right)=0$, we can identify the prior mean and posterior mean from the survey questions A.2 and A.4 since this assumption implies that $\mathrm{E}_{\mathrm{t}=1}\left(G P A_{1 i}\right)=\mathrm{E}_{\mathrm{t}=1}\left(\theta_{i}\right)$ and $\mathrm{E}_{\mathrm{t}=2}\left(G P A_{2 i}\right)=\mathrm{E}_{\mathrm{t}=2}\left(\theta_{i}\right) .{ }^{23}$ The construction

\footnotetext{
${ }^{21}$ These beliefs about $\varepsilon_{\mathrm{ti}}$ may or may not be correct. The assumption that students do not learn about $\varepsilon_{\mathrm{ti}}$ reduces the dimension of the learning problem.

${ }^{22}$ One might think about estimating the distribution of $\varepsilon_{1 \mathrm{i}}$ to use in place of beliefs about $\varepsilon_{1 \mathrm{i}}$. However, assuming that beliefs correspond to the true distribution is not particularly appealing given that the objective of this paper is to examine what can be learned directly from the data without making such assumptions. Further, beliefs constructed in this way would be contradicted directly by the data; for some individuals, the variance of $\theta_{i}+\varepsilon_{1 i}$ elicited in survey question A.2 would be smaller than the estimated variance of $\varepsilon_{1 \mathrm{i}}$.

${ }^{23}$ In the textbook model $\varepsilon_{\mathrm{ti}}$ can be thought of as something like luck. Then, the assumption is that, on average, luck is neither good nor bad. Grades are bounded on the $[0.0,4.0]$ grade interval. While this reality does suggest that certain distributions for $\varepsilon$ cannot be literally correct, it does not by itself directly lead to a contradiction of the assumption that a person believes that $\mathrm{E}\left(\varepsilon_{\mathrm{ti}}\right)=0$. Nonetheless, we stress that this is an assumption made largely for
} 
of $\mathrm{E}\left(G P A_{1 i}\right)$ and $\mathrm{E}\left(G P A_{2 i}\right)$ from the survey questions was described in Sections III and IV.A, respectively, with these variables being referred to in those sections as prior_mean ${ }_{i}$ and posterior_mean , $_{\text {, }}$ respectively.

Thus, while one would be interested, most generally, in how the entire posterior distribution of ability evolves, we focus our attention by attempting to understand how the posterior mean evolves. Under Bayesian updating, a convenient linear form arises for the posterior mean under the assumption that a student's prior distribution of $\theta_{\mathrm{i}}$ is normally distributed and the assumption that the student believes that $\varepsilon_{\mathrm{ti}}$ is normally distributed. Specifically, under these assumptions and the assumption that the student believes that $\mathrm{E}\left(\varepsilon_{\mathrm{ti}}\right)=0$ :

$$
\begin{aligned}
\text { posterior_mean }_{i} & =\mathrm{W}_{1 \mathrm{i}} \cdot \text { prior_mean }_{i}+\mathrm{W}_{2 \mathrm{i}} \cdot G P A_{1 i} \\
& =\text { prior_mean }_{i}+\mathrm{W}_{2 \mathrm{i}} \cdot\left(G P A_{1 i}-\text { prior_mean }_{i}\right)
\end{aligned}
$$

where, denoting $\sigma^{2}{ }_{\varepsilon \mathrm{i}}$ to be the variance of $\varepsilon_{\mathrm{ti}}$,

$$
\mathrm{W}_{1 \mathrm{i}}=\frac{\sigma_{\varepsilon \mathrm{i}}^{2}}{\sigma_{\varepsilon \mathrm{i}}^{2}+\text { prior_variance }_{i}}, \quad \mathrm{~W}_{2 \mathrm{i}}=\frac{\text { prior_variance }_{i}}{\sigma_{\varepsilon \mathrm{i}}^{2}{ }_{\text {prior_variance }}} .
$$

Thus, in the Bayesian model, heterogeneity exists in posterior_mean $n_{i}$ for students with the same $G P A_{l i}$ and prior_mean ${ }_{i}$ because different students assign different weights to $G P A_{l i}$ and prior_mean ${ }_{i}$. We are interested in the model's explanation for why this heterogeneity exists. Equation ( $3 b$ ) shows that $\mathrm{W}_{2 \mathrm{i}}$ can be interpreted as the proportion of the gap between actual and expected performance $\left(G P A_{1 i}\right.$-prior_mean $\left.{ }_{i}\right)$ that the student believes will persist into the future, or, equivalently, is due to permanent factors. Equation (3c) shows that the weight $\mathrm{W}_{2 \mathrm{i}}$ is decreasing in the amount of noise, $\sigma^{2}{ }_{\varepsilon \mathrm{i}}$, that a person believes exists in the grade process. Then, the model produces three implications for why heterogeneity may exist in weights:

Implication 1: A student should put more weight on $G P A_{l i}$ and less weight on prior_mean ${ }_{i}$ if he believes that his better or worse than expected performance is due to permanent factors;

Implication 2: A student should be more likely to believe that his better or worse than expected performance is due to permanent factors if he believes that $\sigma_{\varepsilon i}^{2}$ is small;

convenience with the objective of keeping the subsequent analysis and interpretation as simple/transparent as possible. 
Implication 3: A student should put more weight on $G P A_{1 i}$ and less weight on prior_mean $n_{i}$ if he believes that $\sigma_{\varepsilon i}^{2}$ is small.

Our objective is to use unique survey questions to examine whether heterogeneity in updating in our data is generally consistent with these implications. Before turning to this exercise, we note that, in practice, there is plenty of scope for questioning the textbook model so that providing a formal test of Bayesian updating is difficult using non-experimental data (and not the objective here). For example, the assumption that a student does not observe any portion of $\varepsilon$ directly will not be literally true. If a researcher knew exactly which elements of $\varepsilon$ were known to the individual and could measure these elements, then the researcher could adjust equation (2) to reflect this information. While it would never be possible to observe everything in a person's information set, it seems worthwhile to take into account that the BPS data are unique in providing information about one component of $\varepsilon$ - study effort - that is observed by the student and is perhaps the most important input in the grade production function (S\&S, 2008b)

The manner in which we incorporate study effort into the textbook model is discussed in detail in Appendix B. As described there, what is needed is a comparison of the prior mean, posterior mean, and first semester grade performance holding study effort constant. ${ }^{24}$ To allow such a comparison, we construct adjusted measures of the posterior mean and first semester grade performance, which we refer to as posterior_mean ${ }_{i}^{*}$ and $G P A_{1 i}{ }^{*}$, by holding effort constant at Expected_STUDY $Y_{l i}$, the study effort on which the student person is asked to condition when answering the question from which we construct prior_mean ${ }_{i}($ Question A.2). The approach also requires an assumption about how study effort influences grade performance. We assume that students believe that study effort affects grade performance in a linear manner.

(4) $G P A_{t i}=\alpha_{i} S T U D Y_{t i}+\theta_{i}+\varepsilon_{t i}$

We now turn to examining whether heterogeneity in updating in our data is generally consistent

\footnotetext{
${ }^{24}$ First, a simple comparison of prior_mean $n_{i}$ to posterior_mean $n_{i}$ would produce a misleading view of what a person has learned about his academic ability if the number of hours that the person expects to study per day in semester $\mathrm{t}$ (Expected_STUDY ${ }_{t i}$ ) changes between the beginning of the first semester $(\mathrm{t}=1)$ and the beginning of the second semester $(\mathrm{t}=2)$. Second, a simple comparison of $G P A_{1 i}$ to prior_mean $_{i}$ would provide misleading information about the accuracy of a person's prior beliefs about his ability if a person's study effort in the first semester was different than what he expected at the beginning of the first semester.
} 
with the three implications. For this exercise, we use both our unadjusted measures and the measures adjusted to take into account study effort ${ }^{25}$ Here, we discuss the survey questions that we use and describe, in broad strokes, the main findings. In Appendix $\mathrm{C}$, we detail the results using the unadjusted and adjusted measures.

Implication1 To examine Implication 1 we need a measure of the extent to which a person believes that his better or worse than expected performance is due to permanent factors. This motivated the wording of Question C (Appendix A) which, between the first and second semesters, elicited individual perceptions about the percentage of the $G P A_{1 i}$ - prior_mean ${ }_{i}$ gap that should be attributed to each of the following: better or worse than expected ability (Line A), better or worse than expected preparation (Line B), higher or lower than expected study effort (Line C), and better or worse than expected luck (Line D) ${ }^{26}$

In the model with study effort, the analog to Equation (3b) shows that $\mathrm{W}_{2 \mathrm{i}}$ can be interpreted as the proportion of the gap between actual and expected performance $\left(G P A_{l i}\right.$-prior_mean $\left.{ }_{i}\right)$ that the student believes is due to permanent factors after one takes out the portion of the gap that is due to different than expected study effort. Our measure, which we refer to as $\hat{\mathrm{W}}_{2 \mathrm{i}}$, is created under the assumption that Line $\mathrm{A}$ and Line $\mathrm{B}$ tend to be viewed as persistent and Line $\mathrm{D}$ tends to be viewed as transitory:

$$
\hat{\mathrm{W}}_{2 \mathrm{i}}=\frac{\% \text { line } \mathrm{A}+\% \text { lineB }}{\% \text { line } \mathrm{A}+\% \text { lineB }+\% \text { lineD }}, \quad \hat{\mathrm{W}}_{1 \mathrm{i}}=1-\hat{\mathrm{W}}_{2 \mathrm{i}} .
$$

Consistent with Implication 1, Appendix C shows that, when forming the posterior mean, students put significantly more weight on their first semester grade point average and significantly less weight on their prior

\footnotetext{
${ }^{25}$ In the adjusted model with study effort, the starting point analogous to equation (1) comes from replacing posterior_mean ${ }_{i}$ with the adjusted measure posterior_mean ${ }_{i}{ }^{*}$ and $G P A_{I i}$ with the adjusted measure $G P A_{I i}{ }^{*}$. The results are shown in Column 1 of Table 6 . Both the null hypothesis that $\beta_{1}=0$ and the null hypothesis that $\beta_{2}=0$ continue to be rejected at all traditional significance levels with t-statistics of 11.098 and 8.091, respectively.

${ }^{26}$ In order to keep this experimental question manageable, if a student performed worse (better) than expected, the survey question abstracts from the possibility that the student might have found expected ability to be better (worse) than expected or expected preparation to be better (worse) than expected or study effort to be higher (lower) than expected or luck to be better (worse) than expected.
} 
mean when $\hat{\mathrm{W}}_{2 \mathrm{i}}$ is high.

Implication 2 To test the second implication from the previous section we need a measure of how much noise students believe exists in the grade process. This motivated question D (Appendix A) which at the beginning of the first semester asked individuals about the importance of "luck" in the determinations of grades, where we have attempted to define luck to contain a wide range of transitory factors that would be contained in $\varepsilon$. If "luck" is roughly synonymous with $\varepsilon$ (and under the previous assumption that students believe that $\mathrm{E}\left(\varepsilon_{\mathrm{ti}}\right)=0$ ), the sum of the responses on lines D.2 and D.3 of question D would represent a person's beliefs about $\operatorname{Pr}\left(\varepsilon_{t i}\right.$ $\left.>.25 \mid \varepsilon_{t i}>0\right) .{ }^{27}$ Although this interpretation of the sum of the responses on lines D.2 and D.3 is certainly not literally correct, the sum should be strongly (positively) correlated with $\sigma^{2}{ }_{\varepsilon i}$ so, acknowledging the obvious abuse of notation, we refer to the sum as $\hat{\sigma}_{\varepsilon i}^{2}$. As discussed in Appendix C, we find strong evidence of a negative relationship between $\hat{W}_{2 i}$ and $\hat{\sigma}_{\varepsilon i}^{2}$ that is consistent with Implication 2 .

$\underline{\text { Implication } 3}$ Examining the third implication requires that we examine the influence of our proxy $\hat{\sigma}_{\varepsilon i}^{2}$ directly. Consistent with implication 2, Appendix C shows that, when forming the posterior mean, students put significantly more weight on their first semester grade point average and significantly less weight on their prior mean when they believe that $\sigma_{\varepsilon i}^{2}$ is small. We note that the evidence in support of this implication is particularly useful for future work since $\hat{\sigma}_{\varepsilon i}^{2}\left(\right.$ unlike the measure $\left.\hat{\mathrm{W}}_{2 \mathrm{i}}\right)$ represents a structural, environmental belief. As such, this finding could allow a more useful specification for the learning process to be embedded in a behavioral model of the drop-out decision.

\section{Direct evidence about the reasons for drop-out.}

The outcome variable we use, dropout ${ }_{i}$, is an indicator of whether students in our sample (who were all enrolled at the beginning of the second semester and typically finished the second semester) leave school before the beginning of the second year. We find that $17 \%$ (56 out of 325 ) of the students in our sample do so.

\footnotetext{
${ }^{27}$ This measure has a mean (standard deviation) of .511 (.250) for the sample of 211 students in Table 7.
} 
The drop-out decision at the end of the second semester can be written

(6) dropout $_{i}=1$ iff dropout $_{i}^{*}=\mathrm{E}_{2}\left(\mathrm{~V}_{\mathrm{N}}\right)-\mathrm{E}_{2}\left(\mathrm{~V}_{\mathrm{S}}\right)>0$,

where $E_{2}\left(V_{S}\right)$ is the expected present value of lifetime utility at the end of the second semester $(t=2)$ of returning to college and $\mathrm{E}_{2}\left(\mathrm{~V}_{\mathrm{N}}\right)$ is the expected present value of lifetime utility at the end of the second semester of entering the workforce.

While, in reality, dropout $_{i}$ represents the solution to a non-trivial dynamic programming problem, the estimation of a structural model of the drop-out decision is beyond the scope of this paper. Instead we employ straightforward linear probability models, so that the contribution of the analysis here comes entirely from the unique nature of the data. Although we have a specific interest in understanding the importance of learning, note that Equation (6) motivates specifications in which variables related to a person's state at the end of the second semester, rather than what the person has learned during the year, enter as independent variables. In terms of state variables related to academic ability, a student's cumulative grade point average at the end of the second semester $\left(G P A_{-}\right.$Cumulative $\left.{ }_{i}\right)$ influences $\mathrm{E}_{2}\left(\mathrm{~V}_{\mathrm{S}}\right)$ because it represents a student's current stock of grades and a student's beliefs about the mean of his ability/grade distribution at the end of the second semester influences $E_{2}\left(V_{S}\right)$ because it represents beliefs about the future flow of grades. ${ }^{28}$ The former is essentially just an average of $G P A_{1 i}$ and $G P A_{2 i}$ and is obtained directly from administrative data. For the latter, we construct a self-reported version $E O Y$ mean $_{i}$ from an end-of-the-second-semester survey question that is identical to Survey Questions A.2 and A.4 except that it elicited beliefs about grades in the fall term of the second year by asking students to "assume that you return to Berea and that the classes you take in the fall term are of equal difficulty as those you took this year." 29

Two hundred sixty-eight students have legitimate values of both EOY_mean ${ }_{i}$ and GPA_Cumulative . We remove an additional six people who had GPA_Cumulative ${ }_{i}<1.5$, and, therefore, were forced to leave

\footnotetext{
${ }^{28}$ While the entire belief distribution could influence decisions, we focus on the mean of this distribution for simplicity.

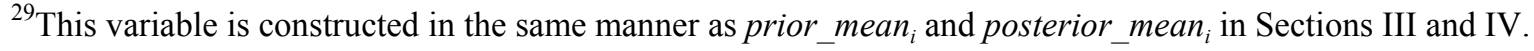


school. Regressing dropout $_{i}$ on GPA_Cumulative ${ }_{i}$ in the first column of Table 9 indicates that GPA_Cumulative ${ }_{i}$ is a statistically significant and quantitatively important predictor of dropout $_{i}$ (t-statistic $=-5.772)$. Regressing dropout $_{i}$ on $E O Y \_$mean $_{i}$ in the second column of Table 9 indicates that $E O Y \_m e a n_{i}$ is a statistically significant and quantitatively important predictor of dropout $_{i} \quad$ (t-statistic $\left.=-5.615\right)$. More importantly, Column 3 of Table 9 shows that $E O Y \_$mean $_{i}$ continues to be significant predictor of dropout $_{i}(\mathrm{t}-$ statistic -2.349) when it is included in a specification that also includes GPA_Cumulative ${ }_{i}(\mathrm{t}$-statistic -2.673$)$. Thus, the results when we use beliefs about academic ability/grade performance from self-reported expectations data are consistent with the theoretical implication that actual grade performance and beliefs about future grade performance should both influence the drop-out decision. ${ }^{30}$

The potential value of the self-reported expectations data becomes particularly evident after viewing the results in Column 4 of Table 9 in which the self-reported EOY_mean ${ }_{i}$ is replaced by a Rational Expectations estimate RE_EOY_mean ${ }_{i}$ which is constructed as described in Appendix D. Inconsistent with the simple theory, the RE results indicate that beliefs about future grade performance do not affect the drop-out decision after conditioning on $G P A_{-}$Cumulative ${ }_{i}$. The estimated effect of $R E \_E O Y \_m e a n_{i}$ is quantitatively very small (.021) and of an unexpected sign. In addition, both the effect of $R E \_E O Y{ }_{-}$mean ${ }_{i}$ and the effect of $G P A \_$Cumulative ${ }_{i}$ are estimated imprecisely. Intuitively, this occurs because GPA_Cumulative ${ }_{i}$ both enters the drop-out specification itself and is forced to play a central role in the construction of $R E \_E O Y \_m e a n_{i}$.

Of relevance for thinking about various explanations for drop-out that might serve as alternatives to explanations involving academic ability/grade performance, in S\&S (2008a) we find that, although credit constraints likely influence the drop-out decision of some students at Berea, the large majority of attrition is unrelated to credit constraints. We focus most of our attention here on the most prominent remaining explanation - that students often leave school because they find it to be stressful or unenjoyable - although we

\footnotetext{
${ }^{30}$ One could perhaps construct a scenario in which only current grade performance matters. However, given that future grade performance will account for roughly $75 \%$ of a person's final grade point average, it seems only natural to believe that both current grades and beliefs about future grades should be important determinants of drop-out.
} 
do return later to a discussion of other possible explanations. ${ }^{31}$ At the end of the second semester, the BPS elicited information about how enjoyable person i found being in school relative to being out of school using Survey Question E (Appendix A). To simplify the discussion we ignore the qualitative nature of the variable and treat this information as a quantitative, continuous variable $E O Y$ enjoyability ${ }_{i}$ which, in practice, has five possible values (1-5) with higher values representing a situation in which school is less enjoyable. Column 5 of Table 9 shows that students who find school to be unenjoyable are much more likely to drop out, with the estimated effect of EOY_enjoyability ${ }_{i}$ on dropout $_{i}$ being significant at .001 . However, Table 10 shows that $E O Y \_$enjoyability ${ }_{i}$ is very strongly correlated with both $G P A \_C u m u l a t i v e_{i}(\mathrm{p}$-value .0002$)$ and $E O Y \_m e a n_{i}(\mathrm{p}-$ value $<.0001$ ). In Column 6 of Table 9 we see that adding EOY_enjoyability ${ }_{i}$ to the specification that includes $E O Y$ mean $_{i}$, and GPA_Cumulative ${ }_{i}\left(\right.$ Column 3 of Table 9) leaves the estimated effects of EOY_mean ${ }_{i}$, and GPA_Cumulative $e_{i}$ essentially unchanged. However, the estimated effect of EOY_enjoyability decreases by fifty percent relative to the specification in which EOY_enjoyability is included by itself (Column 5), with the p-value associated with a test of the hypothesis of no effect for EOY_enjoyability increasing from .001 (Column 5) to .079 (Column 6). Thus, while the enjoyability of school does itself appear to have some effect on drop-out, much of the drop-out of unhappy students appears to arise because these students also tend to have had poor academic performance and tend to expect to have poor academic performance in the future.

From an interpretation standpoint, an important, open question is whether, to some extent, bad grade performance causes school to be unenjoyable or vice-versa. If unhappiness at school causes bad grade performance, one might expect this to be revealed primarily in substantial decreases in effort (relative to what was expected at the time of entrance) for those who find school to be unenjoyable. The null hypothesis that students with higher values of EOY_enjoyability ${ }_{i}$ study the same amount as other students during the first year can be rejected at significance levels greater than $.085 .^{32}$ However, the relatively small size of the estimated

\footnotetext{
${ }^{31}$ Our data collection is related to the notion that a first pass at collecting measures of social integration in Tinto (1975) might utilize a question along the lines of “Are you enjoying being at university?” Draper (2005).

${ }^{32} \mathrm{We}$ find no differences in the amount that students expected to study at the beginning of the year by EOY_enjoyability ${ }_{i}$ group.
} 
effect implies that the effect of unhappiness on grade performance through this route would be quite small. ${ }^{33}$ Thus, it seems likely that bad grade performance itself is an important underlying cause of dropout.

The results from Column 6 of Table 9 can be used to quantify the role that learning plays in the drop-out decision. The average predicted value of dropout $_{i}$ is $.126 .{ }^{34}$ To examine the amount of drop-out that would have been present if students had learned nothing about their ability after the time of entrance, we compute the average predicted value of dropout $_{i}$ under the counterfactual assumptions that $E O Y \_m e a n_{i}$ is equal to prior_mean $_{i}$ and that GPA_Cumulative ${ }_{i}$ is equal to prior_mean ${ }_{i}$. Under these assumptions we find that the average predicted drop-out rate decreases by $34 \%$ to .083 . To examine the amount of drop-out that would be present if students had learned nothing about the enjoyability of school, we compute the average predicted value of dropout $_{i}$ under the counterfactual assumption that EOY_enjoyability ${ }_{i}$ is equal to what was expected at the beginning of the year (as elicited by Question F in Appendix A and referred to as prior_enjoyability ${ }_{i}$ ). Under this counterfactual, the average predicted drop-out rate decreases by $10 \%$ to $.113 .{ }^{35}$

Thus, the results suggest that what a students learns after arriving at school plays an important role in the drop-out decision, with learning about ability being particularly prominent. Given our specific interest in the role of learning, it is worth exploring whether it is possible to estimate specifications that incorporate learning directly. To motivate the form of these specifications, rewrite equation (6):

$$
\text { dropout }_{i}=1 \text { iff } \text { dropout }_{i}^{*}=\mathrm{E}_{0}\left(\mathrm{~V}_{\mathrm{N}}\right)-\mathrm{E}_{0}\left(\mathrm{~V}_{\mathrm{S}}\right)+\left[\mathrm{E}_{2}\left(\mathrm{~V}_{\mathrm{N}}\right)-\mathrm{E}_{2}\left(\mathrm{~V}_{\mathrm{S}}\right)-\left\{\mathrm{E}_{0}\left(\mathrm{~V}_{\mathrm{N}}\right)-\mathrm{E}_{0}\left(\mathrm{~V}_{\mathrm{S}}\right)\right\}\right]>0 \text {. }
$$

The second term, $\left[\mathrm{E}_{2}\left(\mathrm{~V}_{\mathrm{N}}\right)-\mathrm{E}_{2}\left(\mathrm{~V}_{\mathrm{S}}\right)-\left\{\mathrm{E}_{0}\left(\mathrm{~V}_{\mathrm{N}}\right)-\mathrm{E}_{0}\left(\mathrm{~V}_{\mathrm{S}}\right)\right\}\right]$, captures what the student has learned, between the time of college entrance $(t=0)$ and the end of the second semester $(t=2)$, about the expected benefits of being in

\footnotetext{
${ }^{33} \mathrm{~A}$ one unit increase in EOY_enjoyability $i$ is associated with a .139 decrease in a student's average study hours per day in the first year.

${ }^{34}$ Note that 33 of $262(12.6 \%)$ of the 262 person subsample have dropout $_{i}$ equal to one. This percentage becomes $14.6 \%$ if we add back in the students who satisfied the condition of having legitimate values of both EOY_mean

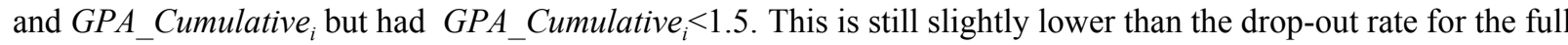
325 person sample $(17 \%)$, in part because a few students drop-out during the second semester.

${ }^{35}$ The analysis of this section has included only individuals who have GPA_Cumulative ${ }_{i}$ greater than 1.5. Including the remainder of the individuals and reestimating Column 6 of Table 9, we find that the drop-out rate would have decreased by $39 \%$ due to learning about ability. The decrease in the drop-out rate due to learning about the enjoyability of school is predicted to remain at $10 \%$.
} 
school . To allow comparability with our earlier results, we begin by focusing on learning about ability as measured by the difference in mean expectations $E O Y$ mean $_{i}-$ prior_mean $_{i}$ and learning about the enjoyability of school as measured by EOY_enjoyability - prior_enjoyability $_{i}$. The presence of the first term, $\mathrm{E}_{0}\left(\mathrm{~V}_{\mathrm{N}}\right)-\mathrm{E}_{0}\left(\mathrm{~V}_{\mathrm{S}}\right)$, indicates that, in order for a specification in which learning enters directly to be sensible, it must also include information about how far each student was from the margin of indifference at the time of college entrance. ${ }^{36}$ Since, all else being equal, students who are closer to the margin of indifference at the time of entrance will be less likely to graduate, we are able to take into account possible differences in this "initial condition" by including each student's perception about the probability that he will graduate at the time of college entrance ( prob_grad $_{i}$ ) which we obtain from Question B in Section III.

The results in the first column of Table 11 indicate that there is information in the self-reported initial conditions variable $p r o b \_\operatorname{grad}_{i}$; students with higher values of prob_grad ${ }_{i}$ are significantly less likely to drop out conditional on what they learn about their ability and the enjoyability of school with a test of the hypothesis that prob_grad ${ }_{i}$ has no effect having a p-value of .039. The effect of learning about ability is highly significant with the null hypothesis that EOY_mean ${ }_{i}$ - prior_mean ${ }_{i}$ has no effect on drop-out yielding a tstatistic of -4.225 . The effect of learning about the enjoyability of school is just significant at $5 \%$.

We can use this model to re-examine our earlier results which quantify the role that learning plays in the drop-out decision. The average predicted value of dropout $_{i}$ is essentially the same as before, .127. Assuming no learning about ability (setting EOY_mean ${ }_{i}$ - prior_mean ${ }_{i}$ equal to zero for all students) leads to an average predicted drop-out value of .103. Assuming no learning about the enjoyability of school (setting EOY_enjoyability - prior_enjoyability $_{i}$ equal to zero for all students) leads to an average predicted drop-out value of .117. In the second column of Table 11 we add the additional learning term GPA_Cumulative ${ }_{i}$ prior_mean $_{i}$ to account for learning about the stock of grades at the end of the first year. Using this model

\footnotetext{
${ }^{36}$ That is, whether a student ultimately ends up above the margin of indifference and out of school (dropout $\left.{ }_{i}^{*}>0\right)$ depends on how far below the margin of indifference he was at the time of entrance (i.e. how negative $\mathrm{E}_{0}\left(\mathrm{~V}_{\mathrm{N}}\right)$ $\mathrm{E}_{0}\left(\mathrm{~V}_{\mathrm{S}}\right)$ is) and, given this, whether the amount he learns after college entrance pushes him over the margin of indifference.
} 
leads to an average predicted drop-out value of .089 when we assume that no learning about ability takes place

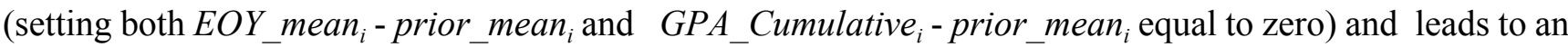
average predicted drop-out value of .119 when we assume that no learning about the enjoyability of school takes place. Thus, the results are very consistent with what was found using equation (6).

The BPS also collects information about other factors that could influence a student's state at the end of the first year. In the last column of Table 9 we add, to the specification in Column 6 , variables representing a person's beliefs about the financial returns to schooling at the end of the year $\left(\right.$ EOY_returns $\left._{i}\right)$, whether the student has a parent that lost a job during the year (parental_job_loss $s_{i}$ ), and a student's health on a four point scale where higher values represent better health $\left(E O Y \_\right.$health $) .{ }^{37}$ A student's health and whether the student has a parent that lost a job may influence how enjoyable it is to be in school. Indeed, Table 10 shows a statistically significant correlation between EOY_enjoyability ${ }_{i}$ and EOY_health E $_{i}$ and between

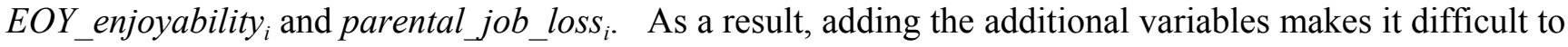
interpret the estimated effect of EOY_enjoyability ${ }_{i}$. However, the primary message from Column 6 of Table 9 - that previous academic performance and beliefs about ability/future grade performance play a central role in the drop-out decision - remains strong with the estimated effect of EOY_mean ${ }_{i}$ and GPA_Cumulative $e_{i}$ staying roughly the same when the new variables are added. In the last column of Table 11, we add variables representing what a person has learned about the financial returns to schooling during the academic year $\left(E O Y \_r e t u r n s_{i}-\right.$ prior_returns $\left._{i}\right)$, the change in the student's health during the year $\left(E O Y \_h e a l t h_{i}\right.$ prior_health ${ }_{i}$ ), and the parental job loss variable (parental_job_loss $s_{i}$ ) to the specification in Column 1 of Table 11. Again we find that adding these variables has little effect on the estimated importance of learning about ability $\left(E O Y \_\right.$mean $_{i}-$ prior_mean $)$.

\footnotetext{
${ }^{37}{ }^{37} O Y \_$returns $s_{i}$ is the difference, at the end of the first year, between a student's beliefs about the median earnings he would receive if he graduated from college with a 3.0 grade point average and the student's beliefs about the

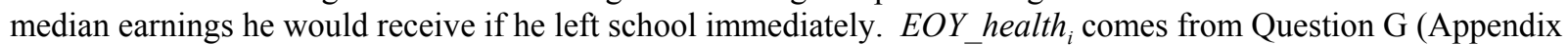
A).
} 


\section{A study of poorly performing students}

Our results indicate that what a student learns about his academic ability plays an important role in whether he drops out of school. Thus, from a policy standpoint it is important to understand to what extent students update their beliefs in a reasonable fashion. Here we study this issue by focusing on the group of students who are of particular concern to policymakers - students with poor grade performance in the first semester. Specifically, in order to continue to take advantage of Question C of Appendix A (which examines how well a student performs relative to expected), we examine students who have values of GPA $A_{1 i}$-Prior_Mean $n_{i}$ in the bottom third of our sample. ${ }^{38}$ One hundred of the 109 students in the bottom third correctly recognized in Question C.1 that their first semester grades were worse than expected. On average, these 100 students have a $G P A_{1 i}$-Prior_Mean ${ }_{i}$ gap of -1.25 points. Table $12 \mathrm{~A}$ uses Question C.3 to show how much of this gap these students believe, on average, should be attributed to worse than expected ability/preparation, worse than expected luck, and lower than expected study effort. Comparing the numbers in Table 12A to the numbers in Table 12B for students in the top third of the GPA $A_{1 i}$-Prior_Mean ${ }_{i}$ distribution raises the possible concern that students in the bottom third may be incorrectly dismissing new information about their ability; students in the bottom third attribute, on average, only $27 \%$ of the GPA $A_{1 i}-P r i o r_{-} M e a n_{i}$ to worse than expected ability/preparation whereas students in the top third attribute, on average, $67 \%$ of the

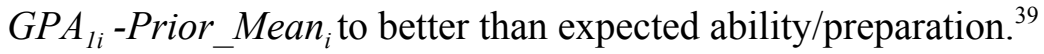

\section{VI.A. Are beliefs about the reasons for poor academic performance accurate?}

In order to examine whether the beliefs in Table 12A are accurate we must determine what proportion of the average $G P A_{1 i}$-Prior_Mean ${ }_{i}$ gap should actually be attributed to each of the three possibilities. Because the decomposition exercise requires assumptions, the results should be viewed as an attempt to provide some

\footnotetext{
${ }^{38}$ These students have a $G P A_{1 i}$-Prior_Mean ${ }_{i}<-.56$. We note that, because most students tend to be very optimistic

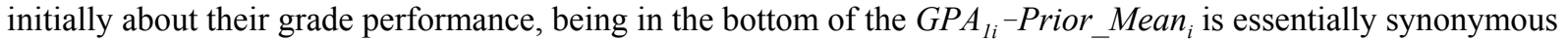
with being in the bottom of the $G P A_{I i}$ distribution; the average value of $G P A_{I i}$ is 2.012 for the former group and is 1.924 for the latter group.

${ }^{39}$ In results not shown, we find that differences in updating between these groups is broadly consistent with this finding; students in the bottom third put significantly less weight on $G P A_{1 i}$ than students in the top third in the construction of the posterior mean.
} 
rough evidence about whether, on average, students are generally able to comprehend the underlying reasons for their worse than expected performance.

\section{The portion of the gap that should be attributed to lower than expected study effort}

As seen in Table 12a, on average, students in the bottom third of the GPA $A_{1 i}$-Prior_Mean ${ }_{1 i}$ distribution believe that the majority of their grade gap (55\%) should be attributed to the fact that they did not study as hard as expected. Our results provide striking evidence that they are indeed correct in believing that their effort was substantially lower than expected; while Question A.1 indicates that, on average, students in the bottom third expected to study 3.98 hours per day, our time-diaries show that they actually studied only 3.07 hours a day. ${ }^{40}$ Further, as a bit of an aside, individuals in the top third of the GPA $A_{l i}$-Prior_Mean ${ }_{l i}$, who, on average, were much less likely to report that studying more than expected was an important reason for their better than expected grade performance $(21 \%)$, did indeed have initial beliefs about studying that were much more accurate; while, on average, students in the top third expected to study 3.44 hours per day, in reality they studied 3.57 hours per day. ${ }^{41}$

As discussed earlier, in S\&S (2008b) we find that an extra hour of studying per day increases first semester grade point average by .36. Using this estimate, the fact that, on average, students in the bottom third studied .91 hours a day less than expected implies that $(.91 * .36 / 1.25) \%=26 \%$ of the average $G P A_{1 i}$ Prior_Mean ${ }_{1 i}$ gap should be attributed to the fact that these students studied less than expected. This number is shown in Table $13 .^{42}$

\footnotetext{
${ }^{40}$ The null hypothesis that the average actual amount studied is the same as the average expected amount studied leads to rejection at all traditional significance levels with a standard normal test statistic of 3.65.

${ }^{41}$ The null hypothesis that the average actual amount studied is the same as the average expected amount studied cannot be rejected at any traditional significance levels with a standard normal test statistic of .57.

${ }^{42}$ One possible explanation for the finding that individuals in the bottom third significantly overstate the role of effort is that students have perceptions about the causal effect of studying on academic performance that are not be the same as the estimated causal effect in S\&S (2008b). Survey question H (Appendix A) not only allows heterogeneity across students but also allows a particular student's belief about the effect of an additional hour of studying to vary with the number of hours that he is currently studying. We find that, on average, students believe that, if they had studied as much as they expected, their grade performance would be higher by .51. Using the information from Question $\mathrm{H}$ as if it is the truth (in place of our estimate of .36) and recomputing the numbers in Table 13, we find that the proportion of the gap that should actually be attributed to less effort than expected increases from $26 \%$ to $41 \%$ (with the perceived amount of $55 \%$ from Table $12 \mathrm{~A}$ ).
} 


\section{The portion of the gap that should be attributed to worse than expected luck}

The intuition underlying our approach for determining the portion of the gap that should be attributed to worse than expected luck is that a group of students who, on average, have bad luck in the first semester should see their average grades rebound in the second semester (after adjusting for study effort in the two semesters). Using our estimate of .36 for $\alpha$ and referring to equation (4):

(8) $G P A_{l i}=.36 S t u d y_{1 i}+\theta_{\mathrm{i}}+\varepsilon_{1 \mathrm{i}}$

(9) $G P A_{2 i}=.36 S t u d y_{2 i}+\theta_{\mathrm{i}}+\varepsilon_{2 \mathrm{i}}$.

By assumption, $\mathrm{E}\left(\varepsilon_{1 \mathrm{i}}\right)=0$ and $\mathrm{E}\left(\varepsilon_{2 \mathrm{i}}\right)=0$. Further, for this section we think of the transitory components $\varepsilon_{1 \mathrm{i}}$ and $\varepsilon_{2 \mathrm{i}}$ as representing short-term luck, in which case it is reasonable to assume that $\varepsilon_{1 \mathrm{i}}$ is independent of $\varepsilon_{2 \mathrm{i}}{ }^{43}$ The question of the degree to which students in the bottom third have bad luck in the first semester is then a question of how much the average value of $\varepsilon_{1 \mathrm{i}}$ is less than zero for these students.

Differencing equation (9) from equation (8) and rearranging yields (10) $G P A_{1 i}-G P A_{2 i}-.36\left(S_{t u d y}-S_{1 i} t u d y_{2 i}\right)=\varepsilon_{1 \mathrm{i}}-\varepsilon_{2 \mathrm{i}}$.

Thus, the left hand side of equation (10) represents the difference in a person's "luck" between the two semesters. Conditional on being in the bottom third of the GPA $A_{l i}$-Prior_Mean ${ }_{1 i}$ distribution, the average value of $\varepsilon_{1 \mathrm{i}}$ may indeed be negative. However, under the assumption that $\varepsilon_{1 \mathrm{i}}$ is independent of $\varepsilon_{2 \mathrm{i}}$, individuals in the bottom third have $\mathrm{E}\left(\varepsilon_{2 \mathrm{i}}\right)=0$. Thus, the intuition underlying our approach is that, if individuals in the bottom third have bad luck, on average, in the first semester, then we should see the average grades of this group rebound in the second semester (after taking into account any change in study effort). Specifically, taking expectations in equation (10) and rearranging, we get an equation for the average first semester luck

\footnotetext{
${ }^{43}$ This is a non-trivial assumption. There would seem to be little doubt that things that could be characterized as short-term luck are likely to be an important component of the $\varepsilon$ 's. For example, fitting this description would be bad matches with teachers, sampling variation in test taking, inopportune short-term sicknesses etc. Examples of things that would not fit this description are, for example, the ability to choose courses and long-term sicknesses. The effect of course choice is mitigated to a large extent by the reality that many first-year courses are mandatory under a general studies curriculum and our data reveal very little evidence of long-term health problems that develop after the beginning of the first year. However, it is not possible to rule out other possible examples as well (e.g., problems with living arrangements that last a full year). As a result we do not believe that this assumption is literally true.
} 
(11) $\mathrm{E}\left(\varepsilon_{1 \mathrm{i}}\right)=\mathrm{E}\left[G P A_{1 i}-G P A_{2 i}-.36\left(S t u d y_{1 i}-S t u d y_{2 i}\right)\right]$

Thus, an estimate of $\mathrm{E}\left(\varepsilon_{1 \mathrm{i}}\right)$ for the bottom third can be computed as the sample average value of $G P A_{l i}-$ $G P A_{2 i}-.36\left(S T U D Y_{1 i}-S T U D Y_{2 i}\right)$ for individuals in the bottom third.

For students in the bottom third, there is evidence of the rebound that would indicate bad luck in the first semester. For this group, the sample averages of $G P A_{1 i}$ and $G P A_{2 i}$ are 1.98 and 2.44, respectively, and the sample averages of $S T U D Y_{1 i}$ and $S T U D Y_{2 i}$ are 3.07 and 2.99 , respectively. These numbers imply that students in the bottom third have a sample average of -.49 for $G P A_{1 i}-G P A_{2 i}-.36\left(S T U D Y_{1 i}-S T U D Y_{2 i}\right)$. Thus, as shown in Table 13, bad luck accounts for $(.49 / 1.25) \%=39 \%$ of the average gap.

\section{The portion of the gap that should be attributed to worse than expected ability/preparation}

The portion of the average gap that should be attributed, on average, to lower than expected ability/preparation is the residual between the average total gap and the portions that should be attributed to lower than expected effort and bad luck. Thus, as shown in Table 13, 100\%-39\%-26\% $=35 \%$ is the proportion of the average $G P A_{l i}$-Prior_Mean ${ }_{l i}$ gap that should be attributed to worse ability/preparation than expected.

\section{$\underline{\text { Discussion }}$}

A comparison of Table 12A to Table 13 indicates that, on average, this group of poorly performing students have a reasonably accurate perception of the extent to which the $G P A_{1 i}$-Prior_Mean gap should be attributed to worse than expected ability/academic preparation ( $27 \%$ perceived vs. $35 \%$ actual). The fact that, if anything, individuals tend to understate the role of these presumably persistent factors should perhaps be reassuring to policymakers worried that students might leave school prematurely when things go badly. With respect to the remaining portion of the $G P A_{1 i}$-Prior_Mean gap, perhaps somewhat surprisingly, students tend to take much personal responsibility for their poor performance in the sense that they attribute a larger percentage of the gap than they should to lower than expected effort (55\% perceived versus $26 \%$ actual) and a lower percentage of the gap than they should to bad luck (18\% perceived versus $39 \%$ actual).

\section{B. Do forecasts improve for this group?}

For students in the bottom third, Table 4 shows that the average value of Posterior_Mean ${ }_{i}(2.923)$ is 
much closer to the average value of $G P A_{2 i}(2.457)$ than the average value of Prior_Mean $n_{i}(3.267)$ is to the average value of $\mathrm{GPA}_{1 \mathrm{i}}(2.012){ }^{44}$ Similarly, for this group, the average value of $\mid$ Posterior_Mean $_{i}-G P A_{2 i} \mid$ is .720 while the average value of $\mid$ Prior_Mean $_{i}-G P A_{l i} \mid$ is $.1 .277 . .^{45}$ The improved prediction occurs, in part, because the grades of this group improve in the second semester, but also because students in this group have significantly revised their beliefs about grade performance - a null hypothesis that the average value of Posterior_Mean ${ }_{i}$ is the same as the average value of Prior_Mean ${ }_{i}$ is rejected at all traditional significance levels. Approximately $1 / 3$ of the gap that remains between the average value of Posterior_Mean ${ }_{i}$ and the average value of $G P A_{2 i}$ can be attributed to the fact that, although students in this group do revise beliefs about how much they will study, they remain too optimistic; although, on average, students in this group have a value Expected_STUDY ${ }_{2 i}$ of 3.391 (down from an average Expected_STUDY ${ }_{1 i}$ of 3.978), the average value of STUDY $2 i$ is 2.992 .

\section{Conclusion}

The paper shows that learning about ability plays a major role in the drop-out decision process. We leave the estimation of a dynamic, learning model of the drop-out decision to future work, although the results here suggest the value of taking advantage of self-reported expectations data to reduce the reliance on assumptions in such a behavioral model.

\footnotetext{
${ }^{44} \mathrm{~A}$ test rejects, at all traditional significance levels, the null hypothesis that there is no difference between $\mathrm{E}\left(\right.$ Posterior_Mean $\left._{i}\right)-\mathrm{E}\left(G P A_{2 i}\right)$ and $\mathrm{E}\left(\right.$ Prior_Mean $\left._{i}\right)-\mathrm{E}\left(G P A_{l i}\right)$.

${ }^{45} \mathrm{~A}$ test rejects, at all traditional significance levels, the null hypothesis that there is no difference between the average value of $\mid$ Posterior_Mean $_{i}-G P A_{2 i} \mid$ and the average value of $\mid$ Prior_Mean $_{i}-G P A_{1 i} \mid$.
} 


\section{References}

Altonji, Joseph. "The Demand for and Return to Education When Education Outcomes are Uncertain," Journal of Labor Economics, 1993, vol. 11, no. 1, 48-83.

Barsky, Robert, Kimball, Miles, Juster, F. Thomas, and Shapiro, Matthew. "Preference Parameters and Behavioral Heterogeneity: An Experimental Approach in the Health and Retirement Survey," The Quarterly Journal of Economics, May 1997, 537-579.

Beekhoven, S., De Jong, U. And Van Hout, H. "Explaining Academic Progress Via Combining Concepts of Integration Theory and Rational Choice Theory, Research in Higher Education, 43(5), October 2002, 577-600.

Carneiro, Pedro, Hansen, Karsten, and Heckman, James, "Estimating Distributions of Counterfactuals with an Application to the Returns to Schooling and Measurement of the Effect of Uncertainty on Schooling Choice," International Economic Review, 2005

Cunha, Flavio, Heckman, James, and Navarro, Salvador, "Separating Uncertainty from Heterogeneity in Life Cycle Earnings," Oxford Economic Papers, 2005, 57(2), 191-261.

Das, Marcel and van Soest, Arthur, "Expected Versus Realized Income Expectations: A Test of the Rational Expectations Hypothesis," unpublished manuscript, 2000.

Delavande, Adeline, "Pill, Patch or Shot? Subjective Expectations and Birth Control Choice," unpublished manuscript, 2006.

Dominitz, Jeff. "Earnings Expectations, Revisions, and Realizations," The Review of Economics and Statistics, August 1998, 374-388.

Dominitz, and Hung, "Evidence on the Formation of Information Cascades," unpublished manuscript, 2003.

Dominitz, Jeff and Manski, Charles. "Eliciting Student Expectations of the Returns to Schooling," Winter 1996, $1-26$.

Dominitz, Jeff and Manski, Charles. "Using Expectations Data to Study Subjective Income Expectations," Journal of American Statistical Association, September 1997, 855-867.

Dominitz, Jeff and Manski, Charles. "How Should We Measure Consumer Confidence (sentiment)? Evidence form the Michigan Survey of Consumers," Working paper 9926, National Bureau of Research, 2003.

Draper, Stephen, “Tinto's Model of Student Retention,” Notes:

http://www.psy.gla.ac.uk/ steve/localed/tinto.html (2005).

Heckman, James, Lochner, L, and Todd, Petra. "Earnings Functions, Rates of Return and Treatment Effects: The Mincer Equation and Beyond." In Handbook of the Economics of Education, ed. By E. Hanushek and F. Welch. Amsterdam: North-Holland, 307-458.

Heckman, James and S. Navarro, 2007.” Dynamic Discrete Choice and Dynamic Treatment Effects,” Journal of Econometrics, 136 (2007): 341-396 
Juster, T. "Consumer Buying Intentions and Purchase Probability: An Experiment in Survey Design,” Journal of the American Statistical Association, 61, 658-696.

Lochner, Lance, "Individual Perceptions of the Criminal Justice System," American Economic Review, 97(1), March 2007.

Madeira, Carlos, “Forecasting Academic Achievement,” working paper, Northwestern University, 2007.

Manski, Charles, "Schooling as Experimentation: a reappraisal of the post-secondary drop-out phenomenon,"Economics of Education Review, Volume 8 number 4, 1989, 305-312.

Manski, C., "Identification of Decision Rules in Experiments on Simple Games of Proposal and Responses," European Economic Review, 46 (2002), 880-91.

Manski, C., “Measuring Expectations,” Econometrica, 72 (5), (2004), 1329-1376.

National Center for Education Statistics, "Getting Ready to Pay for College: What Students and Their Parents Know about the Cost of College Tuition and What They Are Doing to Find Out," Publication \# 2003030, September, 2003.

Stange, Kevin, “An Empirical Examination of the Option Value of Schooling," working paper, University of California Berkeley, 2007.

Stinebrickner, Todd and Stinebrickner, Ralph, "Understanding Educational Outcomes of Students from Low-Income Families: Evidence from a Liberal Arts College with a Full Tuition Subsidy Program," Journal of Human Resources, 38(3) Summer (2003), 591-617.

Stinebrickner, Todd and Stinebrickner, Ralph, "Time-Use and College Outcomes," Journal of Econometrics, 121 (1-2) July-August (2004), 243-269.

Stinebrickner, Todd and Stinebrickner, Ralph, "The Effect of Credit Constrains on the College Drop-Out Decision: A Direct Approach Using a New Panel Study,” American Economic Review. December (2008a)

Stinebrickner, Todd and Stinebrickner, Ralph, "The Causal Effect of Studying on Academic Performance," Frontiers in Economic Policy and Analysis (Frontiers), Berkeley Electronic Press (2008b).

Stinebrickner, Todd and Stinebrickner, Ralph, "The Effect of Credit Constrains on the College Drop-Out Decision: A Direct Approach Using a New Panel Study," American Economic Review. December (2008).

Tinto, V. "Dropout from Higher Education: A Theoretical Synthesis of Recent Research, Review of Educational Research, Winter, 1975, Vol. 45, No. 1, 89-125.

van der Klaauw, Wilbert and Wolpin, Kenneth, "Social Security and the Retirement and Savings Behavior of Low Income Households," Journal of Econometrics, (forthcoming).

van der Klaauw, Wilbert, "On the Use of Expectations Data in Estimating Structural Dynamic Models: An Analysis of Career Choices," unpublished manuscript, 2000.

Wolpin, Kenneth, “Commentary on 'Analysis of Choice Expectations in Incomplete Scenarios', by C.F. Manski,’Journal of Risk and Uncertainty 19, issues 1-3, 1999, 67-69. 
Zafar, Basit,"How do College Students Form and Revise Expectations about Major-Specific Outcomes, working paper, 2008. 
Table 1A

FIRST SEMESTER GPA - BELIEFS AND ACTUAL $(n=325)$

\begin{tabular}{|c|c|c|}
\hline $\mathbf{1}^{\text {st }}$ semester GPA interval & Subjective probability & $\begin{array}{c}\text { Sample } \\
\text { probability }\end{array}$ \\
\hline$[3.5,4.0]$ & $.401(.256)$ & .234 \\
\hline$[3.0,3.5)$ & $.329(.175)$ & .302 \\
\hline$[2.5,3.0)$ & $.160(.132)$ & .200 \\
\hline$[2.0,2.5)$ & $.072(.073)$ & .123 \\
\hline$[1.0,2.0)$ & $.025(.035)$ & .108 \\
\hline$[0.0,1.0)$ & $.012(.022)$ & .033 \\
\hline $\begin{array}{c}\text { prior_mean }_{i} \text { : Approximate subjective mean of GPA } \mathrm{A}_{1 \mathrm{i}} \\
\text { sample average (sample standard deviation) }\end{array}$ & $3.220(.292)$ & \\
\hline $\begin{array}{c}\text { Approximate subjective standard deviation of } \mathrm{GPA}_{1 \mathrm{i}} \\
\text { sample average (sample standard deviation) }\end{array}$ & $.532(.195)$ & \\
\hline $\begin{array}{l}\text { Actual GPA }{ }_{1 \mathrm{i}} \\
\quad \text { sample average (sample standard deviation) }\end{array}$ & & $2.879(.784)$ \\
\hline
\end{tabular}

Note: First column shows average subjective probability (standard deviation) of having $\mathrm{GPA}_{1}$ in each category. Second column shows proportion of sample with actual $\mathrm{GPA}_{1 \mathrm{i}}$ in each category.

Table 1B

FIRST SEMESTER GPA - BELIEFS AND ACTUAL

High School Grade Point Average Greater Than Median ( $\mathrm{n}=157)$

\begin{tabular}{lcc}
\hline $\mathbf{1}^{\text {st }}$ semester GPA interval & Subjective probability & Sample probability \\
\hline$[3.5,4.0]$ & $.454(.245)$ & .338 \\
{$[3.0,3.5)$} & $.310(.158)$ & .369 \\
{$[2.5,3.0)$} & $.139(.102)$ & .153 \\
{$[2.0,2.5)$} & $.064(.060)$ & .089 \\
{$[1.0,2.0)$} & $.022(.031)$ & .031 \\
{$[0.0,1.0)$} & $.010(.020)$ & .019 \\
prior_mean ${ }_{i}$ : Approximate subjective mean of GPA & \\
$\quad$ sample average (sample standard deviation) & $3.275(.266)$ & \\
Approximate subjective standard deviation of GPA & & \\
$\quad$ sample average (sample standard deviation) & $.526(.192)$ & $3.164(.661)$ \\
Actual GPA & & \\
$\quad$ sample average (sample standard deviation) & & \\
\hline
\end{tabular}

Note: See Note Table 1A

High School Grade Point Average not observed for 11 of 325 students in sample. 
Table 1C

FIRST SEMESTER GPA - BELIEFS AND ACTUAL

High School Grade Point Average Less Than Median ( $\mathrm{n}=157)$

\begin{tabular}{lcc}
\hline $\mathbf{1}^{\text {st }}$ semester GPA interval & $\begin{array}{c}\text { Subjective } \\
\text { probability }\end{array}$ & Sample probability \\
\hline$[3.5,4.0]$ & $.339(.250)$ & .121 \\
{$[3.0,3.5)$} & $.355(.188)$ & .236 \\
{$[2.5,3.0)$} & $.186(.155)$ & .248 \\
{$[2.0,2.5)$} & $.080(.083)$ & .153 \\
{$[1.0,2.0)$} & $.072(.038)$ & .191 \\
{$[0.0,1.0)$} & $.017(.024)$ & .051 \\
& & \\
prior_mean ${ }_{i}$ : Approximate subjective mean of GPA & \\
$\quad$ sample average (sample standard deviation) & $3.161(.301)$ & \\
Approximate subjective standard deviation of GPA ${ }_{1 \mathrm{i}}$ & $.538(.198)$ & \\
$\quad$ sample average (sample standard deviation) & & $2.579(.802)$ \\
Actual GPA & & \\
$\quad$ sample average (sample standard deviation) & & \\
\hline
\end{tabular}

Note: See Note Table 1A

High School Grade Point Average not observed for 11 of 325 students in sample.

Table 2

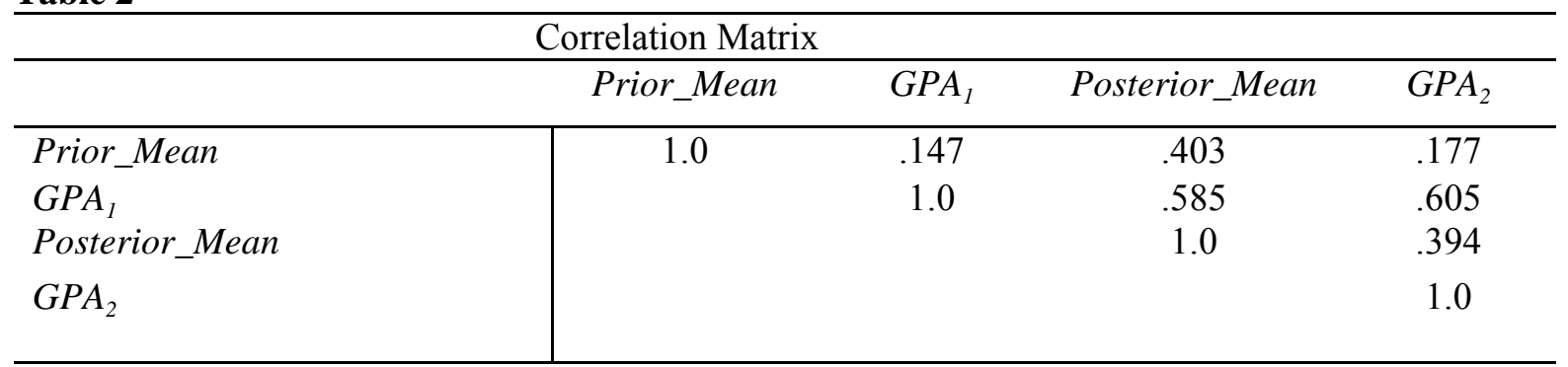

Note: High School Grade Point Average not observed for 11 of 325 students in sample. 
Table 3

SECOND SEMESTER GPA - BELIEFS $(\mathrm{n}=325)$

\begin{tabular}{lc}
\hline 2nd semester GPA interval & $\begin{array}{c}\text { Subjective } \\
\text { probability }\end{array}$ \\
\hline$[3.5,4.0]$ & $.311(.278)$ \\
{$[3.0,3.5)$} & $.365(.205)$ \\
{$[2.5,3.0)$} & $.200(.174)$ \\
{$[2.0,2.5)$} & $.084(.101)$ \\
{$[1.0,2.0)$} & $.031(.058)$ \\
{$[0.0,1.0)$} & $.009(.025)$ \\
& $3.140(.357)$ \\
posterior_mean ${ }_{i}:$ Approximate subjective mean of GPA & \\
$\quad$ sample average (sample standard deviation) & $.477(.194)$ \\
Approximate subjective standard deviation of GPA & \\
$\quad$ sample average (sample standard deviation) & \\
\hline
\end{tabular}

Table 4 Descriptive statistics for entire sample $(n=325)$ and subgroups

\begin{tabular}{|c|c|c|c|c|c|}
\hline Variable & $\begin{array}{l}\text { Full Sample } \\
\text { mean (s.d.) }\end{array}$ & $\begin{array}{c}\text { Top third } \\
G P A_{1} \\
\text { mean (s.d.) }\end{array}$ & $\begin{array}{c}\text { Bottom third } \\
\qquad G P A_{1} \\
\text { mean (s.d.) }\end{array}$ & $\begin{array}{c}\text { Top third } \\
G P A_{1} \text {-prior_mean } \\
\text { mean (s.d.) } \\
\end{array}$ & $\begin{array}{c}\text { Bottom third } \\
G P A_{1}-\text { prior_mean } \\
\text { mean (s.d.) }\end{array}$ \\
\hline prior_mean & $3.220(.292)$ & $3.278(.291)$ & $3.199(.295)$ & $3.123(.311)$ & $3.267(.267)$ \\
\hline posterior_mean & $3.140(.357)$ & $3.386(.287)$ & $2.886(.303)$ & $3.293(.307)$ & $2.923(.306)$ \\
\hline$G P A_{1}$ & $2.879(.784)$ & $3.650(.225)$ & $1.924(.553)$ & $3.541(.354)$ & $2.012(.605)$ \\
\hline$G P A_{2}$ & $2.929(.772)$ & $3.398(.560)$ & $2.380(.783)$ & $3.320(.668)$ & $2.457(.786)$ \\
\hline
\end{tabular}

Each entry shows sample average (sample standard deviation)

Students in bottom third of GPA1 distribution have GPA1<2.64

Students in top third of GPA1 distribution have GPA1 $>3.30$

Students in top third of $\mathrm{GPA}_{1}$-prior_mean distribution have $\mathrm{GPA}_{1}$-prior_mean>.09.

Students in bottom third of $\mathrm{GPA}_{1}$-prior_mean distribution have $\mathrm{GPA}_{1}$ - - prior_mean<-.56. 
Table 5

DETERMINANTS OF POSTERIOR MEAN(column 1) AND POSTERIOR MEAN* (column 2)

\begin{tabular}{lcc}
\hline Independent Variable & $\begin{array}{c}\text { dependent variable } \\
\text { posterior_mean } \\
\text { estimate (std. error) } \\
\mathrm{n}=325\end{array}$ & $\begin{array}{c}\text { dependent variable } \\
\text { posterior_mean* } \\
\text { estimate (std. error) } \\
\mathrm{n}=291\end{array}$ \\
\hline Constant & $1.158(.166)^{* *}$ & $.323(.040)^{* *}$ \\
Prior_Mean $_{G P A_{1}}$ & $.396(.051)^{* *}$ & $.597(.053)^{* *}$ \\
$G P A_{1}{ }^{*}$ & $.245(.019)^{* *}$ & \\
Study equation $(8)_{\mathrm{C}}$ & & $.344(.042)^{* *}$ \\
$\sigma^{2}{ }_{\mu}$ & & \\
$\sigma^{2}{ }_{v}$ & & $3.249(.110)^{* * *}$ \\
& & $1.20(.103)^{* *}$ \\
\end{tabular}

The first column is estimated by OLS and uses all sample observations.

The second column is a measurement error model estimated by Maximum

Likelihood (using approach of Section IV.C.2) and using all observations

for which a person reports legitimate values of Expected_STUDY ${ }_{1 i}$ and

Expected_STUDY $Y_{2 i}$

*significant at .10

**significant at .05 
DETERMINANTS OF Posterior_Mean* (Maximum Likelihood)

\begin{tabular}{|c|c|c|c|}
\hline $\begin{array}{l}\text { I nd e p e n d e n t } \\
\text { Variable }\end{array}$ & $\begin{array}{c}\text { estimate } \\
\text { (std. error) } \\
\text { n=191 }\end{array}$ & $\begin{array}{c}\text { estimate } \\
\text { (std. error) } \\
\text { n=191 }\end{array}$ & $\begin{array}{c}\text { estimate } \\
\text { (std. error) } \\
\text { n=191 }\end{array}$ \\
\hline Constant & $.661(.388)^{*}$ & $.550(.399)$ & $.814(.370)^{* *}$ \\
\hline $\begin{array}{l}\text { Prior_Mean } \\
\text { GPA }_{1 i}{ }^{*}\end{array}$ & $\begin{array}{l}.517(.112)^{* *} \\
.316(.039)^{* *}\end{array}$ & $\begin{array}{l}.494(.115)^{* *} \\
.176(.068)^{* *}\end{array}$ & $\begin{array}{r}.357(.129)^{* *} \\
.446(.064)^{* *}\end{array}$ \\
\hline Prior_Mean ${ }_{i} x \hat{W}_{1 i}$ & & $.177(.085)^{* *}$ & \\
\hline 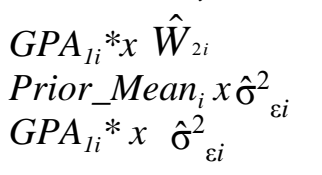 & & $.198(.091)^{* *}$ & $\begin{array}{l}.248(.122)^{* *} \\
-.303(.127)^{* *}\end{array}$ \\
\hline $\begin{array}{l}\text { Study equation (8) } \\
\mathrm{C} \\
\sigma^{2}{ }_{\mu} \\
\sigma^{2}{ }_{v}\end{array}$ & $\begin{array}{l}3.524(.124)^{* *} \\
1.272(.121)^{* *} \\
1.608(.072)^{* *}\end{array}$ & $\begin{array}{l}3.522(.125)^{* *} \\
1.270(.123)^{* *} \\
1.609(.072)^{* *}\end{array}$ & $\begin{array}{l}3.527(.125)^{* *} \\
1.260(.122)^{* *} \\
1.611(.072)^{* *}\end{array}$ \\
\hline & $\begin{array}{c}\text { Log Like } \\
-1328.637\end{array}$ & $\begin{array}{l}\text { Log Like } \\
-1326.037\end{array}$ & $\begin{array}{l}\text { Log Like } \\
-1314.874\end{array}$ \\
\hline
\end{tabular}

The sample contains the 191 students who a) correctly recognized in Question C.1 whether they had performed better or worse than expected in the first semester; b) did not have a percentage of 100 on line c of Question C.2 (or C.3); c) provided legitimate information about Expected_STUDY $Y_{1 i}$ and Expected_STUDY ${ }_{2 i}$. The first column repeats the results in Column 2 of Table 5 for the smaller sample here. Estimation is by maximum likelihood (using approach of Section IV.C.2).

*significant at .10

**significant at .05 
Table 7

\section{DETERMINANTS OF Posterior Mean (OLS)}

\begin{tabular}{|c|c|c|c|}
\hline Independent Variable & $\begin{array}{c}\text { estimate } \\
\text { (std. error) } \\
n=211\end{array}$ & $\begin{array}{c}\text { estimate } \\
\text { (std. error) } \\
n=211\end{array}$ & $\begin{array}{c}\text { estimate } \\
\text { (std. error) } \\
\text { n=211 }\end{array}$ \\
\hline $\begin{array}{l}\text { Constant } \\
\text { Prior_Mean }_{i} \\
\text { GPA }_{1 i} \\
\text { Prior_Mean }_{i} \times \hat{W}_{1 i} \\
\text { GPA }_{1 i} \times \hat{W}_{2 i} \\
\text { Prior_Mean }_{i} \times \hat{\sigma}_{\varepsilon i}^{2} \\
\text { GPA }_{1 i} \times \hat{\sigma}_{\varepsilon i}^{2}\end{array}$ & $\begin{array}{l}1.203(.223)^{* *} \\
.380(.068)^{* *} \\
.242(.022)^{* *}\end{array}$ & $\begin{array}{c}1.181(.223)^{* *} \\
.362(.069)^{* *} \\
.169(.045)^{* *} \\
.083(.048)^{*} \\
.101(.055)^{*}\end{array}$ & $\begin{array}{l}1.352(.223)^{* *} \\
.221(.089)^{* *} \\
.387(.057)^{* *}\end{array}$ \\
\hline & $\mathrm{R}^{2}=.436$ & $\mathrm{R}^{2}=.445$ & $\mathrm{R}^{2}=.466$ \\
\hline
\end{tabular}

The sample contains the 211 students who correctly recognized in Question C.1 whether they had performed better or worse than expected in the first semester and did not have a percentage of 100 on line c of Question C.2 (or C.3). Estimation is by Ordinary Least Squares.

*significant at 10

$* *$ significant at .05 
Table 8

\begin{tabular}{lc} 
& RELATIONSHIP BETWEEN $\hat{W}_{1 i}$ and $\hat{\sigma}^{2}$ \\
\hline Independent Variable & dependent variable \\
& $\hat{\mathrm{W}}_{1}$ \\
& estimate (std. error) \\
$\mathrm{n}=211$ \\
\hline Constant & $.158(.063)^{* *}$ \\
$\hat{\sigma}_{\varepsilon i}^{2}$ & $.299(.110)^{* *}$ \\
\end{tabular}

For a description of the sample see the note in Table 6 . 
Table 9 DETERMINANTS OF DROPOUT:

The effect of a student's state at end of first year

DETERMINANTS OF dropout d $_{i}$ (OLS)

\begin{tabular}{|c|c|c|c|c|c|c|c|}
\hline $\begin{array}{l}\text { I n d e p e n d e n t } \\
\text { Variable }\end{array}$ & $\begin{array}{c}\text { estimate } \\
\text { (std. } \\
\text { error) } \\
n=262 \\
(1)\end{array}$ & $\begin{array}{c}\text { estimate } \\
\text { (std. } \\
\text { error) } \\
n=262 \\
(2)\end{array}$ & $\begin{array}{c}\text { estimate } \\
\text { (std. } \\
\text { error) } \\
\mathrm{n}=262 \\
(3)\end{array}$ & $\begin{array}{c}\text { estimate } \\
\text { (std. } \\
\text { error) } \\
n=245 \\
(4)\end{array}$ & $\begin{array}{c}\text { estimate } \\
\text { (std. } \\
\text { error) } \\
n=261 \\
(5)\end{array}$ & $\begin{array}{c}\text { estimate } \\
\text { (std. error) } \\
\mathrm{n}=261 \\
(6)\end{array}$ & $\begin{array}{c}\text { estimate } \\
\text { (std. error) } \\
\mathrm{n}=260 \\
(7)\end{array}$ \\
\hline Constant & $\begin{array}{l}.671^{* *} \\
(.096)\end{array}$ & $\begin{array}{c}1.113 * * \\
(.176)\end{array}$ & $\begin{array}{c}1.024 * * \\
(.178)\end{array}$ & $\begin{array}{l}.647 * * \\
(.173)\end{array}$ & $\begin{array}{c}.015 \\
(.039)\end{array}$ & $\begin{array}{l}.920 * * \\
(.195)\end{array}$ & $\begin{array}{l}.970 * * \\
(.206)\end{array}$ \\
\hline GPA_Cumulative $_{i}$ & $\begin{array}{c}-.182 * * \\
(.031)\end{array}$ & & $\begin{array}{c}-.114 * * \\
(.042)\end{array}$ & $\begin{array}{c}-.194 * * \\
(.112)\end{array}$ & & $\begin{array}{c}-.105^{* *} \\
(.042)\end{array}$ & $\begin{array}{c}-.110^{* *} \\
(.043)\end{array}$ \\
\hline$E_{-} Y_{-}$Mean $_{i}$ & . & $\begin{array}{c}-.315^{* *} \\
(.056)\end{array}$ & $\begin{array}{c}-.177 * * \\
(.075)\end{array}$ & & & $\begin{array}{c}-.171 * * \\
(.076)\end{array}$ & $\begin{array}{c}-.156^{* *} \\
(.078)\end{array}$ \\
\hline$R E \_E O Y \_M e a n_{i}$ & & & & $\begin{array}{l}.021 \\
(.154)\end{array}$ & & & \\
\hline school_enjoyability $_{i}$ & & & & & $\begin{array}{l}.062 * * \\
(.019)\end{array}$ & $.033 *(.019)$ & $\begin{array}{l}.026 \\
(.019)\end{array}$ \\
\hline EOY_health $_{i}$ & & & & & & & $\begin{array}{l}-.019 \\
(.031)\end{array}$ \\
\hline$E_{\text {EY_returns }}$ & & & & & & & $\begin{array}{l}-.029 \\
(.037)\end{array}$ \\
\hline parental_job_loss $_{i}$ & $\mathrm{R}^{2}=.113$ & $\mathrm{R}^{2}=.108$ & $\mathrm{R}^{2}=.132$ & $\mathrm{R}^{2}=.104$ & $\mathrm{R}^{2}=.038$ & $\mathrm{R}^{2}=.146$ & $\begin{array}{c}.077 \\
(.061) \\
\mathrm{R}^{2}=.155\end{array}$ \\
\hline
\end{tabular}

Table shows results of linear probability models with dependent variable dropout $_{i}$.

Explanatory variables measure student's state at end of first year.

Sample is as described in Section V.

Column 4 has less observations since, as discussed in Appendix C, constructing

RE_EOY_Mean ${ }_{i}$ involves use of HSGPA and ACT which are missing for some observations.

*significant at .10

$* *$ significant at .05 
Table 10 Correlation Matrix $(n=260)$

\begin{tabular}{|c|c|c|c|c|c|c|c|}
\hline Variable & dropout $_{i}$ & $\begin{array}{c}\text { GPA- } \\
\text { Cumulative }_{i}\end{array}$ & $\begin{array}{l}\text { EOY_ }_{-} \\
\text {Mean }_{i}\end{array}$ & $\begin{array}{c}\text { EOY_ } \\
\text { enjoyability }\end{array}$ & $\begin{array}{c}\text { parental_job } \\
\text { _loss }_{i}\end{array}$ & EOY_health $_{i}$ & $E_{\text {EOYreturns }}$ \\
\hline dropout $_{i}$ & 1.00 & & & & & & \\
\hline GPA_Cumulative $_{i}$ & $\begin{array}{c}-.339 * * \\
.0000\end{array}$ & 1.00 & & & & & \\
\hline EOY_Mean $_{i}$ & $\begin{array}{l}-.335^{* *} \\
.0000\end{array}$ & $\begin{array}{l}.676^{* *} \\
.0000\end{array}$ & 1.00 & & & & \\
\hline EOY_enjoyability ${ }_{i}$ & $\begin{array}{l}.195 * * \\
.001\end{array}$ & $\begin{array}{l}-.232 * * \\
.0002\end{array}$ & $\begin{array}{c}-.251 * * \\
.0000\end{array}$ & 1.00 & & & \\
\hline parental_job_loss ${ }_{i}$ & $\begin{array}{l}.115^{*} \\
.063\end{array}$ & $\begin{array}{c}-.048 \\
.437\end{array}$ & $\begin{array}{l}-.056 \\
.364\end{array}$ & $.172 * *$ & 1.00 & & \\
\hline$E_{\text {EOYhealth }}$ & $\begin{array}{c}-.107 * \\
.084\end{array}$ & $\begin{array}{l}.089 \\
.148\end{array}$ & $\begin{array}{l}.227 * * \\
.0002\end{array}$ & $\begin{array}{c}.005 \\
-.109 * \\
.078\end{array}$ & $\begin{array}{c}-.103 * \\
.097\end{array}$ & 1.00 & \\
\hline$E_{\text {EOYreturns }}$ & $\begin{array}{l}-.978 \\
.204\end{array}$ & $\begin{array}{l}.020 \\
.739\end{array}$ & $\begin{array}{l}.070 \\
.260\end{array}$ & $\begin{array}{c}-.156^{* *} \\
.011\end{array}$ & $\begin{array}{c}-.079 \\
.119\end{array}$ & $\begin{array}{c}-.044 \\
.472\end{array}$ & 1.00 \\
\hline
\end{tabular}

The first number in each box is the sample correlation between two variables. The second number is a p-value from a test that the population correlation between two variables is zero.

*significant at 10

$* *$ significant at .05 
Table 11 DETERMINANTS OF DROPOUT:

The effect of learning during the first year

\begin{tabular}{|c|c|c|c|}
\hline Independent Variable & $\begin{array}{c}\text { estimate } \\
\text { (std. error) } \\
n=259\end{array}$ & $\begin{array}{c}\text { estimate } \\
\text { (std. error) } \\
n=259\end{array}$ & $\begin{array}{c}\text { estimate } \\
\text { (std. error) } \\
n=248\end{array}$ \\
\hline Constant & $\begin{array}{l}.302 * * \\
(.102)\end{array}$ & $\begin{array}{l}.280 * * \\
(.101)\end{array}$ & $\begin{array}{c}.272^{* *} \\
(.103)\end{array}$ \\
\hline prob_grad $_{i}$ & $\begin{array}{l}-.242^{* *} \\
(.116)\end{array}$ & $\begin{array}{c}-.230 * * \\
(.115)\end{array}$ & $\begin{array}{r}-.228 * * \\
(.117)\end{array}$ \\
\hline EOY_mean ${ }_{i}-$ prior_mean $_{i}$. & $\begin{array}{r}-.251 * * \\
(.059)\end{array}$ & $\begin{array}{l}-.107 * \\
(.060)\end{array}$ & $\begin{array}{r}-.238 * * \\
(.061)\end{array}$ \\
\hline$E_{\text {EO_enjoyability }}$ - prior_enjoyability & $\begin{array}{l}.031^{*} \\
(.19)\end{array}$ & $\begin{array}{l}.023 \\
(.018)\end{array}$ & $\begin{array}{c}.029 \\
(.018)\end{array}$ \\
\hline GPA_Cumulative $_{i}-$ prior_mean $_{i}$ & & $\begin{array}{c}-.117 * * \\
(.044)\end{array}$ & \\
\hline EOY_health $_{i}-$ prior_health $_{i}$ & & & $\begin{array}{l}-.042 \\
(.033)\end{array}$ \\
\hline$E_{\text {EO_returns }}$-prior_returns $s_{i}$ & & & $\begin{array}{l}-.004 \\
(.035)\end{array}$ \\
\hline parental_job_loss $_{i}$ & $\mathrm{R}^{2}=.086$ & $\mathrm{R}^{2}=.113$ & $\begin{array}{c}.094 \\
(.063) \\
\mathrm{R}^{2}=.098\end{array}$ \\
\hline
\end{tabular}

Table shows results of linear probability models with dependent variable dropout ${ }_{i}$. Explanatory variables measure how much a person has learned during first year. sample as described in Section V.

*significant at .10

$* *$ significant at .05 
Table 12A

Percentages from Question C.3

100 individuals who have GPA1-PRIOR MEAN in bottom third and correctly indicated on Question C.1 that grades were lower than expected

\section{Independent Variable}

$\mathrm{a}+\mathrm{b})$ Worse than expected ability/preparation

c) Lower than expected study effort

d) Worse than expected luck mean

(standard deviation)

$55.1 \%(35.1)$

$17.7 \%(27.2)$

Table 12B

Percentages from Question C.2

79 individuals who have GPA1-PRIOR MEAN in top third and correctly indicated on Question C.1 that grades were higher than expected

Independent Variable

$\mathrm{a}+\mathrm{b})$ Better than expected ability/preparation

c) Higher than expected study effort

d) Better than expected luck mean

(standard deviation)

$67.1 \%(34.3)$

$21.4 \%(27.6)$

$11.5 \%(25.0)$

$\underline{\text { Table } 13}$

Estimates of actual importance of categories in Question O

100 individuals who have GPA1-PRIOR MEAN in bottom third and correctly indicated on Question O that grades were lower than expected

Independent Variable

$\mathrm{a}+\mathrm{b})$ Worse than expected ability/preparation

c) Lower than expected study effort

d) Worse than expected luck mean

(standard deviation)
$35 \%$

$26 \%$

$39 \%$ 


\section{Appendix A: Survey Questions}

Question A.1. During your first year of college, how many hours do you expect to spend in the following activities on an average weekday (Monday-Friday).

Activity

\section{- $\quad \underline{\text { Avg }}$ \\ $\underline{\text { Weekday hours }}$}

1. Studying and Homework

2. Sleeping

3. School Athletics, Clubs, other school activities

Question A.2. We realize that you do not know exactly how well you will do in classes. However, we would like to have you describe your beliefs about the grade point average that you expect to receive in the first semester.

Given the amount of study-time you indicated in question A.1, please tell us the percent chance that your grade point average will be in each of the following intervals. That is, for each interval, write the number of chances out of 100 that your final grade point average will be in that interval.

Note: The numbers on the six lines must add up to 100 .

Interval $\quad \underline{\text { Percent Chance (number of chances }}$ out of 100).

$[3.0,3.49]$

$[2.5,2.99]$

$[2.0,2.49]$

$[1.0,1.99]$

$[0.0, .99]$

Note: $A=4.0, B=3.0, C=2.0, D=1.0, F$ 
Question A.3. During the second semester, how many hours do you expect to spend in the following activities on an average weekday (Monday-Friday).

Activity

$$
\underline{\text { Avg Weekday hours }} \text { - }
$$

1. Studying and Homework

2. Sleeping

3. School Athletics, Clubs, other school activities

Question A.4. We realize that you do not know exactly how well you will do in classes. However, we would like to have you describe your beliefs about the grade point average that you expect to receive in the second semester.

Given the amount of study-time you indicated in question A.3, please tell us the percent chance that your grade point average will be in each of the following intervals. That is, for each interval, write the number of chances out of 100 that your final grade point average will be in that interval.

Note: The numbers on the six lines must add up to 100 .

Interval Percent Chance (number of chances out of 100).

$[3.5,4.00]$

$[3.0,3.49]$

$[2.5,2.99]$

$[2.0,2.49]$

$[1.0,1.99]$

$[0.0, .99]$

Note: $A=4.0, B=3.0, C=2.0, D=1.0, F$ 
Question C.1. Circle the one that is true

a). I received grades in the Fall term that were higher than I had expected to get when I came to Berea.

b). I received grades in the Fall term that were lower than I had expected to get when I came to Berea.

If you circled a), GO TO Question C.2 below.

If you circled b), GO TO Question C.3 below.

Question C.2. (Answer this question if you circled that grades better than expected in Question C.1.)

Please circle those reasons why you think you received grades in Fall term that were higher that you had expected.

A) My ability is better than I thought it was when I came to Berea.

B) I am better prepared for Berea College than I thought I was when I came to Berea.

C) I studied harder than I had expected I would when I came to Berea .

D) I had better luck than I expected when I came to Berea in that those things that

influence grades but were out of my control turned out to be very much in my favor.

Now consider the difference between the grades you received in Fall term and the grades you had expected. On the lines to the right of the reasons, write the percentage of this difference that you would attribute to each of the reasons you circled. (The items you did not circle should have zero percentage or be left blank.) Note: The numbers on the lines should add to 100.

Question C.3. (Answer this question if you circled that grades are worse than expected in Question C.1)

Circle those reasons why you think you received grades in Fall term that were lower than what that you had expected.

A) My ability is not as good as I thought it was when I came to Berea.

B) I am not as well prepared for Berea College as I thought I was when I came to Berea.

C) I did not study as hard as I thought I would when I came to Berea.

D) I had worse luck than I expected when I came to Berea in that those things that influence grades but were out of my control turned out to be hurting my grades.

Now consider the difference between the grades you received in Fall term and the grades you had expected. On the lines to the right of the reasons, write the percentage of this difference that you would attribute to each of the reasons you circled. (The items you did not circle should have zero percentage or be left blank.) Note: The numbers on the lines should add to 100. 
Question D. Your grades are influenced by your academic ability/preparation and how much you decide to study. However, your grades may also be influenced to some extent by good or bad luck which may vary from term to term and may be out of your control. Examples of "luck" may include 1) The quality of the teachers you happen to get and how hard or easy they grade; 2) Whether you happened to get sick (or didn't get sick) before important exams; 3) Whether a noisy dorm kept you from sleeping before an important exam; 4) Whether you happened to study the wrong material for exams; 5) Whether unexpected personal problems or problems with your friends and family made it hard to concentrate on classes.

We would like to know how important you think "luck" is in determining your grades in a particular semester. We'll have you make comparisons relative to a semester in which you have "average" luck. Average luck means that a usual number of things go right and wrong during the semester. Assume you took classes at Berea for many semesters.

\section{GOOD LUCK IN A TERM MEANS THAT YOU HAVE BETTER THAN AVERAGE LUCK IN THAT TERM}

\section{Assume for this section that you are in a semester in which you have good luck}

D.1 In what percentage of semesters that you have good luck would good luck raise your grade point average (GPA) by between 0.00 points and 0.25 points compared to a semester in which you received "average" luck.

Note. (If you are taking four courses, good luck would raise your GPA by 0.25 points if good luck led to a full letter grade increase in one of your courses).

D.2 In what percentage of semesters that you have good luck would good luck raise your grade point average (GPA) by between 0.26 points and 0.50 points compared to a semester in which you received "average" luck.

Note: (If you are taking four courses, good luck would raise your GPA by .50 points if good luck led to a full letter grade increase in two of your courses or a two letter grade increase in one of your courses).

D.3 In what percentage of semesters that you have good luck would good luck raise your grade point average (GPA) by 0.51 or more points compared to a semester in which you received "average" luck.

Note: (For a student taking four courses, this would mean that good luck would lead to a full letter grade increase in three or more courses)

The numbers in the three spaces above in the good luck section should add up to 100 (because if you are in a semester where you have good luck, good luck must increase your grades by between 0 and .25 points, or by between .25 and .5 points, or by more than .5 points). 
Question E. Circle the one answer that describes your beliefs at this time.

1. I believe that being in college at Berea will be much more enjoyable than not being in college.

2. I believe that being in college at Berea will be somewhat more enjoyable than not being in college.

3. I believe that I will enjoy being in college at Berea about the same amount as I would enjoy not being in college.

4. I believe that being in college at Berea will be somewhat less enjoyable than not being in college.

5. I believe that being in college at Berea will be much less enjoyable than not being in college.

Question F. Which of the following best describes your beliefs now? Circle the one best answer.

1. I believe that being in college at Berea is much more enjoyable than not being in college.

2. I believe that being in college at Berea is somewhat more enjoyable than not being in college.

3. I have enjoyed being in college at Berea about the same amount as I would have enjoyed not being in college.

4. I believe that being in college at Berea is somewhat less enjoyable than not being $\mathrm{P}$ in college.

5. I believe that being in college at Berea is much less enjoyable than not being in college.

Question G. How would you rate your current health? Poor Fair Good Excellent

Question H. For each of the following possible amounts that you might study, write down the percent chance that you will study that amount and the grade point average you expect to receive if you study that amount.

Number of Study Hours a Day

Expected Grade Point Average

0 hours a day

1 hour a day

2 hours a day

3 hours a day

4 hours a day

5 hours a day

6 or more hours a day 


\section{Appendix B: Adding study effort to the textbook model}

The motivation for taking into account study effort can be seen directly in two observations. First, a simple comparison of prior_mean ${ }_{i}$ to posterior_mean ${ }_{i}$ would produce a misleading view of what a person has learned about his academic ability if the number of hours that the person expects to study per day in semester $\mathrm{t}\left(\right.$ Expected_STUDY $\left.Y_{t i}\right)$ changes between the beginning of the first semester $(\mathrm{t}=1)$ and the beginning of the second semester $(\mathrm{t}=2)$. Second, a simple comparison of $G P A_{1 i}$ to prior_mean $n_{i}$ would provide misleading information about the accuracy of a person's prior beliefs about his ability if a person's study effort in the first semester was different than what he expected at the beginning of the first semester.

Then, what is needed are modified measures of the prior mean, posterior mean, and first semester grade performance in which study effort is held constant. Here we hold effort constant at Expected_STUDY ${ }_{l i}$, the study effort on which the student is asked to condition when answering the question from which we construct prior_mean $_{i}\left(\right.$ Question A.2). Then, our modified measure posterior_mean ${ }_{i}^{*}$ represents the posterior mean that the student would have reported if he had planned to study Expected_STUDY ${ }_{1 i}$ rather than Expected_STUDY ${ }_{2 i}$ in the second semester, and our modified measure $G P A_{1 i}{ }^{*}$ represents the first semester grade point average the person believes he would have received if he had studied Expected_STUDY $Y_{1 i}$ rather than $S T U D Y_{1 i}$ in the first semester. Assuming that students believe that study effort affects grade performance in a linear manner, (B.1) $G P A_{t i}=\alpha_{i} S T U D Y_{t i}+\theta_{i}+\varepsilon_{t i}$,

then the modified measures are given by:

(B.2) posterior_mean ${ }_{i}^{*}=$ posterior_mean $_{i}-\alpha_{i}\left(\right.$ Expected_STUDY $_{2 i}-$ Expected_STUDY $\left._{1 i}\right)$

(B.3) $G P A_{1 i}^{*}=G P A_{1 i}-\alpha_{i}\left(S T U D Y_{1 i}-\right.$ Expected_STUDY $\left.Y_{1 i}\right)$.

Then, using posterior_mean ${ }_{i}{ }^{*}$ in place of posterior_mean ${ }_{i}$ and $G P A_{l i}{ }^{*}$ in place of $G P A_{l i}$, leads to the updated version of equation (3):

$$
\begin{aligned}
& \text { posterior_mean }_{i} *=\mathrm{W}_{1 \mathrm{i}} \cdot \text { prior_mean }_{i}+\mathrm{W}_{2 \mathrm{i}} \cdot G P A_{1 i}{ }^{*} \\
& =\text { prior_mean }_{i}+\mathrm{W}_{2 \mathrm{i}} \cdot\left[G P A_{l i}-\alpha\left(S T U D Y_{1 i}-\text { Expected_STUDY }_{l i}\right)-\text { prior_mean }_{i}\right]
\end{aligned}
$$

Thus, the interpretation of equation (B.5) is similar to (3b) except that $\mathrm{W}_{2 \mathrm{i}}$ can now be interpreted as the proportion of the $G P A_{1 i}$ - prior_mean ${ }_{i}$ gap that the student believes will persist into the future after the portion of the gap that arises because a person studies a different amount than expected in the first semester is removed.

The use of the new measures in equations (B.2) and (B.3) introduces new demands on the data. We assume that $\alpha_{i}$ is homogeneous and use an estimate of .36 that is obtained in S\&S (2008b) from an identification strategy in which we exploit exogenous variation in a student's study effort created by whether his randomly 
assigned roommate brought a video game to school. ${ }^{46}$ Expected_STUDY $Y_{1 i}$ and Expected_STUDY $Y_{2 i}$ are obtained from survey Question A.1 and Question A.3 (Appendix A), respectively. They have means (standard deviations) of 3.47 (1.32) and 3.07 (1.27), respectively, for the sample of 291 students who have valid observations for both of the expected-study variables. STUDY $Y_{1 i}$ represents the average number of hours that a person actually studies per day over all days in the first semester and is not fully observed. What is observed is $S T \hat{U D} Y_{1 i}$ the number of hours that students studied on (up to) four particular days during the first semester on which we administered the 24-hour time diaries (Appendix A) mentioned in Section II. Using $S T \hat{U D} Y_{1 i}$ directly in the construction of $G P A_{1 i}{ }^{*}$ (equation B.3) leads to an errors-in-variables problem in the independent variable $G P A_{1 i}{ }^{*}$. This problem is not easily corrected using textbook methods both because the number of completed time diaries varies across individuals and because the regression specifications that will be used in Section IV.B.3.c include multiple regressors that are functions of $G P A_{1 i}{ }^{*}$.

To address this issue, we take a Maximum Likelihood (MLE) approach of S\&S(2004). Defining N(i) to be the number of time diaries (out of four) that person i completed in the first semester and letting $S_{j i}, \mathrm{j}=1, \ldots$, $\mathrm{N}(\mathrm{i})$ represent the $\mathrm{N}(\mathrm{i})$ observed daily study amounts for person i, a noisy proxy $S T \hat{U} D Y_{1 i}$ of $S T U D Y_{I i}$ can be constructed as:

$$
S T \hat{U} D Y_{1 i}=\frac{1}{\mathrm{~N}(\mathrm{i})} \sum_{j=1}^{N(i)} S_{j i}
$$

The MLE approach deals with the measurement error issue under the assumption that $S_{j i}$ is given by the permanent/transitory process

$$
S_{j i}=\mu_{\mathrm{i}}+v_{\mathrm{ji}}
$$

The permanent component $\mu_{\mathrm{i}}$ represents the average amount that person i studies per day and the transitory component $v_{\mathrm{ji}}$ represents a daily deviation from this average amount. We assume that in the population $\mu_{\mathrm{i}}$ $\sim \mathrm{N}\left(\mathrm{C}, \sigma^{2}{ }_{\mu}\right)$. We assume that $v_{\mathrm{ji}}$ is independent across both $\mathrm{j}$ and $\mathrm{i}$ and that $v_{\mathrm{ji}} \sim \mathrm{N}\left(0, \sigma^{2}{ }_{v}\right)$. Then, analogous to the MLE's derived in the missing data literature, the likelihood contribution for person $i$ is the joint probability of posterior_mean $_{i} *$ and the observed daily study amounts $\mathrm{S}_{1 \mathrm{i}}, \ldots, \mathrm{S}_{\mathrm{N}(\mathrm{i}) \mathrm{i}}$.

Intuitively speaking, if we knew the value of $\mu_{\mathrm{i}}$ for each person and the distribution of $v_{\mathrm{ji}}$, we could integrate out the effect of the missing information in any outcome equation of interest. Our MLE takes into

\footnotetext{
${ }^{46}$ In S\&S (2008b) we find that a person's study effort is strongly influenced by the instrument and find strong support in favor of the validity of the instrument by using a wide variety of survey questions that were designed specifically to document possible violations of the exogeneity condition.
} 
account that, while we do not know the value of $\mu_{\mathrm{i}}$ for each person $\mathrm{i}$, the observed values of $S_{j i}$, when viewed through equation (7), provide evidence about the likelihood of different values of $\mu_{\mathrm{i}}$. More specifically, analogous to the MLE's derived in the missing data literature, the likelihood contribution for person $\mathrm{i}, \mathrm{L}_{\mathrm{i}}$, is the joint probability of posterior_mean ${ }_{i}^{*}$, and the daily study amounts $\mathrm{S}_{1 \mathrm{i}}, \ldots, \mathrm{S}_{\mathrm{N}(\mathrm{i}) \mathrm{i}}$. Noting that, under our permanent/transitory assumption in equation (B.7), each of the daily study amounts and posterior_mean ${ }_{i}^{*}$ are independent conditional on $\mu_{\mathrm{i}}$,

$$
\mathrm{L}_{\mathrm{i}}=\int \mathrm{g}_{1}\left(\mathrm{~S}_{1 \mathrm{i}} \mid \mu_{\mathrm{i}}\right) \cdots \mathrm{g}_{1}\left(\mathrm{~S}_{\mathrm{N}(\mathrm{i}) \mathrm{i}} \mid \mu_{\mathrm{i}}\right) \mathrm{g}_{2}\left(\text { posterior_mean }{ }_{i} * \mu_{\mathrm{i}}\right) \mathrm{h}\left(\mu_{\mathrm{i}}\right) \mathrm{d} \mu_{\mathrm{i}}
$$

where the g's and $\mathrm{h}$ are density functions.

In practice, we assume normality for all densities of relevance, in which case the assumptions above about $\mu_{\mathrm{i}}$ imply that $\mathrm{h} \sim \mathrm{N}\left(\mathrm{C}, \sigma^{2}{ }_{\mu}\right)$ and equation (B.7) implies that $\mathrm{g}_{1} \sim \mathrm{N}\left(\mu_{\mathrm{i}}, \sigma^{2}{ }_{v}\right)$. Defining $\mathrm{N}^{*}$ to be the total number of days in the first semester, STUDY $Y_{1 i}=\frac{1}{\mathrm{~N}^{*}} \sum_{\mathrm{j}=1}^{\mathrm{N}^{*}} \mathrm{~S}_{\mathrm{ji}}=\frac{1}{\mathrm{~N}^{*}} \sum_{\mathrm{j}=1}^{\mathrm{N}^{*}} \mu_{\mathrm{i}}+\frac{1}{\mathrm{~N}^{*}} \sum_{\mathrm{j}=1}^{\mathrm{N}^{*}} v_{\mathrm{ji}} \rightarrow \mu_{\mathrm{i}}$ by the Law of Large Numbers as $\mathrm{N}^{*}$ becomes large. Then, $\mathrm{g}_{2}$ is normally distributed with a variance of $\sigma^{2}$ (the variance of $\mathrm{u}$ in equation 1 of main text) and a mean of $\beta_{0}+\beta_{1}$ prior_mean $_{i}+\beta_{2}\left[G P A_{1 i}-\alpha\left(\mu_{\mathrm{i}}-\right.\right.$ Expected_STUDY $\left.\left._{1 i}\right)\right] .^{47}$

\section{Appendix C: More detail about testing implications}

Implication1 To examine Implication 1 we need a measure of the extent to which a person believes that his better or worse than expected performance is due to permanent factors. This motivated the wording of Question C (Appendix A) which, between the first and second semesters, elicited individual perceptions about the percentage of the $G P A_{1 i}$ - prior_mean ${ }_{i}$ gap that should be attributed to each of the following: better or worse than expected ability (Line A), better or worse than expected preparation (Line B), higher or lower than expected study effort (Line C), and better or worse than expected luck (Line D). ${ }^{48}$

$$
\hat{\mathrm{W}}_{2 \mathrm{i}}=\frac{\% \text { line } \mathrm{A}+\% \text { lineB }}{\% \text { line } \mathrm{A}+\% \text { lineB }+\% \text { lineD }}, \quad \hat{\mathrm{W}}_{1 \mathrm{i}}=1-\hat{\mathrm{W}}_{2 \mathrm{i}}
$$

\footnotetext{
${ }^{47}$ From equation (1) in main text, the mean is $\beta_{0}+\beta_{1}$ prior_mean ${ }_{i}+\beta_{2} G P A_{1 i}{ }^{*}$. Substituting equation (B.2) yields $\beta_{0}$ $+\beta_{1}$ prior_mean $_{i}+\beta_{2}\left[G P A_{l i}-\alpha\left(S T U D Y_{l i}-\right.\right.$ Expected_STUDY $\left.\left._{l i}\right)\right]$. The mean is then obtained because $S T U D Y_{l i} \rightarrow$ $\mu_{\mathrm{i}}$

${ }^{48}$ In order to keep this experimental question manageable, if a student performed worse (better) than expected, the survey question abstracts from the possibility that the student might have found expected ability to be better (worse) than expected or expected preparation to be better (worse) than expected or study effort to be higher (lower) than expected or luck to be better (worse) than expected.
} 
Assuming that Line A and Line B tend to be viewed as persistent and Line D tends to be viewed as transitory yields our measure, which we refer to as $\hat{\mathrm{W}}_{2 \mathrm{i}}$ :

Line C plays no role when the modified model with study effort is used because equation B.5 in Appendix B explicitly takes into account the role of different than expected study effort. ${ }^{49}$ Because equation (C.1) does not use information for Line C, estimates of the weights cannot be constructed if a student assigns a percentage of 100 to line C. Restricting our attention to the 211 students who did not have a percentage of 100 on line C and who correctly recognized in Question C.1 whether they had performed better or worse than expected in the first semester, we find substantial heterogeneity in students' interpretations of the reasons for the $G P A_{1 i}$ - prior_mean ${ }_{i}$ gap; the mean and standard deviation of $\hat{\mathrm{W}}_{2 \mathrm{i}}$ are .688 and .408 , respectively. ${ }^{50}$

To see whether the measure from equation (C.1) can succeed in predicting differences in the posterior mean for students with the same prior mean and same first semester grade performance we use the MLE approach discussed in Appendix B to estimate

(C.2) posterior_mean ${ }_{i}^{*}=\beta_{0}+\beta_{1}$ prior_mean $_{i}+\beta_{2} G P A_{1 i}^{*+} \beta_{3}$ prior_mean $_{i} \times \hat{\mathrm{W}}_{1 \mathrm{ii}}+\beta_{4} G P A_{1 i}^{*} \mathrm{x} \hat{\mathrm{W}}_{2 \mathrm{i}}+\mathrm{u}_{\mathrm{i}}$.

This specification is estimated for the 191 students of our 211 student subsample who also provided valid information about study effort that is needed to construct posterior_mean ${ }_{i}^{*}$ and $G P A_{1 i} *{ }^{51}$ In the second column of Table 6 we find that the point estimates of $\beta_{3}$ and $\beta_{4}$ are of quantitatively important size. For example, a student who believes that his better (or worse) than expected performance is caused entirely by persistent factors $\left(\hat{\mathrm{W}}_{2 \mathrm{i}}=1\right)$ would put 2.1 times as much weight on $G P A_{1 i}{ }^{*}$ as someone who believes that his better (or worse) than expected performance is caused entirely by transitory factors $\left(\hat{\mathrm{W}}_{2 \mathrm{i}}=0\right)$. Further, although as expected $\beta_{3}$ and $\beta_{4}$ are not estimated particularly precisely, the null hypothesis that $\beta_{3}=0$ is rejected at significance levels greater than .038 (t-statistic=2.077) and the null hypothesis that $\beta_{4}=0$ is rejected at significance levels greater than .031 (t-statistic=2.160). The second column of Table 7 shows generally similar

\footnotetext{
${ }^{49}$ This is beneficial because it is hard to know whether students would tend to think of higher or lower than expected study effort as being permanent or transitory (although in theory our data would be helpful for this issue because it contains Expected_STUDY $Y_{I i}$,Expected_STUDY $Y_{2 i}$, and information related to $S T U D Y_{I i}$. Of course, by omitting C, equation (C.1) does make a specific assumption about students' beliefs about the role that higher or lower than expected study effort plays in their better or worse than expected grade performance.

${ }^{50}$ Two hundred forty-six of 325 correctly identified whether they did better or worse than expected with the majority of the incorrect responses coming for individuals whose performance was very close to what they expected. Thirtyfive individuals attributed $100 \%$ of the gap to study effort.

${ }^{51}$ The first column of Table 6 recomputes the results in the second column of Table 5 for the 191 person subsample.
} 
results when the model without study effort is estimated by OLS. ${ }^{52}$

Implication 2 In Table 8 we regress $\hat{W}_{1 i}$ on the measure $\hat{\sigma}_{\varepsilon i}^{2}$ that was described in Section IV.B.3 and find strong evidence of a positive relationship consistent with Implication 2, with the null hypothesis of no relationship being rejected at significance levels greater than $.007 .^{53}$

Implication 3 Examining the third implication requires that we examine the influence of our proxy $\hat{\sigma}_{\varepsilon i}^{2}$ directly. The last column of Table 6 shows results from a regression that is analogous to equation (C.2):

(C.3) posterior_mean ${ }_{i}^{*}=\beta_{0}+\beta_{1}$ prior_mean $_{i}+\beta_{2} G P A_{1 i}^{*+}$

$$
\beta_{3} \text { prior_mean }_{i} \times \hat{\sigma}_{\varepsilon i}^{2}+\beta_{4} G P A_{l i}{ }^{*} \times \hat{\sigma}_{\varepsilon i}^{2}+\mathrm{u}_{\mathrm{i}} \text {. }
$$

The null hypothesis that $\beta_{3}=0$ is rejected at significance levels greater than $.042(\mathrm{t}$-statistic $=2.029)$ and the null hypothesis that $\beta_{4}=0$ is rejected at significance levels greater than .018 (t-statistic $=-2.376$ ). The last column of Table 7 shows even stronger results when we estimate, by OLS, the analog to equation (C.3) that does not take into account study effort. ${ }^{54}$

\footnotetext{
${ }^{52}$ This involves estimating equation (11) with posterior_mean ${ }_{i}$ and $G P A_{1 i}$ in place of posterior_mean ${ }_{i}^{*}$ and $G P A_{1 i}{ }^{*}$. A student who believes that his better (or worse) than expected performance is caused entirely by persistent factors ( $\hat{\mathrm{W}}_{2 \mathrm{i}}=1$ ) would put 1.6 times as much weight on $G P A_{l i}$ as someone who believes that his better (or worse) than expected performance is caused entirely by transitory factors $\left(\hat{\mathrm{W}}_{2 \mathrm{i}}=0\right)$. The null hypothesis that $\beta_{3}=0$ is rejected at significance levels greater than .087 (t-statistic $=1.722$ ) and the null hypothesis that $\beta_{4}=0$ is rejected at significance levels greater than .069 (t-statistic $=1.830)$.

${ }^{53}$ Some additional care is perhaps warranted. In this regression we have not held prior_variance ${ }_{i}$ constant. If $\sigma_{\varepsilon i}^{2}$ and prior_variance ${ }_{i}$ were positively correlated, then Equation (3c) shows that the unconditional correlation between $\mathrm{W}_{1 \mathrm{i}}$ and $\bar{\sigma}_{\varepsilon \mathrm{i}}^{2}$ might not necessarily be positive even though there would exist a well-defined, positive relationship between $\mathrm{W}_{1 \mathrm{i}}$ and $\sigma_{\varepsilon \mathrm{i}}^{2}$ when prior_variance ${ }_{i}$ is held constant. However, we find no evidence that $\sigma_{\varepsilon \mathrm{i}}^{2}$ and prior_variance $_{i}$ are positively correlated. Specifically, constructing a measure of prior_variance ${ }_{i}+\sigma_{\text {ei }}^{2}$ from the uncertainty that a person exhibits about $G P A_{1 i}=\theta_{i}+\varepsilon_{1 i}$ in survey Question A.2, we find no evidence of a relationship between this measure and our proxy for $\sigma_{\varepsilon \mathrm{i}}^{2}$. If there was no relationship between $\sigma_{\varepsilon \mathrm{i}}^{2}$ and prior_variance $_{i}+\sigma_{\varepsilon i}^{2}$ then prior_variance ${ }_{i}$ and $\sigma_{\varepsilon i}^{2}$ would be negatively correlated.

${ }^{54}$ In this case, the null hypothesis that $\beta_{3}=0$ is rejected at significance levels greater than $.018(\mathrm{t}$-statistic $=2.384)$ and the null hypothesis that $\beta_{4}=0$ is rejected at significance levels greater than .004 (t-statistic $=-2.907$ ).
} 


\section{Appendix D. Computing RE_EOY_Mean}

We construct $R E \_E O Y \_$mean $_{i}$ for each person under the assumption that individuals update in a Bayesian manner. Rewriting equation (3) to take into account that the observed noisy signal in this exercise comes from the grade point average for the first full year (instead of just the first semester),

$$
R E \_E O Y \_ \text {mean }_{i}=\mathrm{W}_{1 \mathrm{i}} * \cdot \text { prior_mean }{ }_{i}+\mathrm{W}_{2 \mathrm{i}} * \cdot G P A \_ \text {Cumulative }{ }_{i} \text {. }
$$

What is necessary is to provide values of prior_mean ${ }_{i}, \mathrm{~W}_{1 \mathrm{i}}$, and $\mathrm{W}_{2 \mathrm{i}}$. The Rational Expectations assumption would imply that prior_mean ${ }_{i}$ is the mean grade point average of students who are deemed to be similar person i. Here we assume that people are similar if they have the same sex, high school grade point average, and score on the American College Test (ACT). Thus, prior_mean ${ }_{i}$ can be constructed as a predicted value from a regression of grades on $\mathrm{SEX}_{i}, \mathrm{HSGPA}_{i}$, and $\mathrm{ACT}_{i}$.

Modifying equation (3c) to take into account that $G P A_{-}$Cumulative ${ }_{i}=\left(G P A_{1 i}+G P A_{2 i}\right) / 2$, the weights are given by

$$
\mathrm{W}_{1 \mathrm{i}} *=\frac{\frac{\sigma_{\varepsilon \mathrm{i}}^{2}}{2}}{\frac{\sigma_{\varepsilon \mathrm{i}}^{2}+\text { prior_variance }_{i}}{2}}, \mathrm{~W}_{2 \mathrm{i}} *=\frac{\text { prior_variance }_{i}}{\frac{\sigma_{\varepsilon \mathrm{i}}^{2}}{2}+\text { prior_variance }_{i}} .
$$

Under the RE assumption, prior_variance ${ }_{i}$ can be thought of as the amount of permanent heterogeneity that exists in grades across students that are deemed to be like person i. $\sigma_{\varepsilon i}^{2}$ can be thought of as the amount of transitory variation in grades across students that are deemed to be like person $\mathrm{i}$. Then, it is natural to estimate prior_variance ${ }_{i}$ and $\sigma_{\varepsilon i}^{2}$ using a Random Effects estimator which takes advantage of grade performance in both the first semester and the second semester. Doing so as in the Table Appendix C below leads to an estimate for prior_variance ${ }_{i}$ of .131 and an estimate for $\sigma_{\varepsilon i}^{2}$ of .226 . Then, the weights are .463 and .537 , respectively. 
Table Appendix D Random Effects Estimation of grade performance

Grade Point Average

estimate std. error

\begin{tabular}{lc} 
& $\mathrm{n}=245$ \\
\hline Constant & $.217(.289)^{* *}$ \\
$S E X_{i}$ & $-.099(.067)$ \\
$H S G P A_{i}$ & $.438(.075)^{* *}$ \\
$A C T_{i}$ & $.056(.009)^{* *}$ \\
variance of permanent component & 0.131 \\
variance of transitory component, $\sigma_{\varepsilon i}^{2}$ & 0.226
\end{tabular}

Table contains estimates from a Random Effects Estimation of grade performance in the first and second semesters.

*significant at .10

**significant at .05 